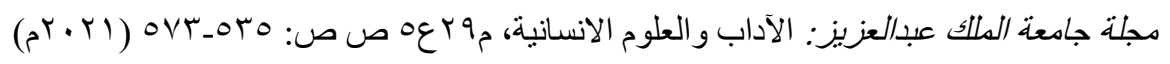

DOI:10.4197/Art.29-5.18

\title{
التصوير الذاتي "السيلفي" كمنبئ بالشخصية النرجسية لذى معلمي وطلبة المرحلة الثانوية بمدينة مكة المكرمة
}

\author{
مريم حميد أحمد اللحياني \\ أستاذ مشارك -قسم علم النفس \\ كلية التربية -جامعة أم القرى
}

مستخص. هدفت هذه الدراسة إلى الكثف عن مستوى كل من التصوير الذاتي السيلفي والثخصية النرجسية، وتحديد العلاقة بينهما، ودرجة التتبؤ بـ"السيلفي" من خلال الثخصية النرجسية، والكثف عن الاختلافات في مستوى " السيلفي" والثخصية النرجسية وفقاً لمتغيرات الدراسة، وكثف الفروق في مستوى "السيلفي" والثخصية النرجسية. حسب متغيرات

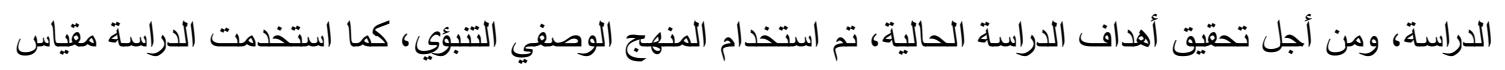

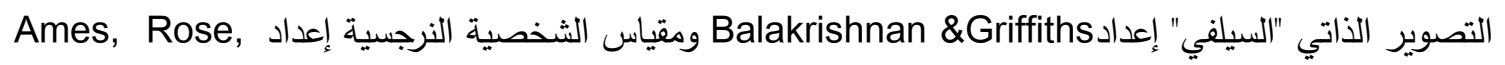
Cameron وتوصلت الدراسة إلى ما يلي: توجد علاقة ارتباطية موجبة ودلالة إحصائية بين الثخصية النرجسية والسيلفي بأبعادها الستة، وجود علاقة ارتباطية موجبة بين الشخصية النرجسية و "السيلفي" بأبعاده الستة، كما تم التتبؤ بنتائج الشخصية النرجسية من خلال التصوير الذاتي "السيلفي" والذي يسهم بنسبة(r ب\%) من التغير الحاصل في الثخصية النرجسية لاى المعلمين، وبنسبة(1/\%) من التغير الحاصل لدى الطلبة. كما كثفت النتائج وجود فروق دالة إحصائياً بين

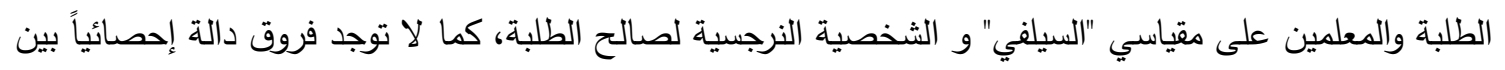
الذكور والإناث على مقياسي التصوير الذاتي "السيلفي" و الثخصية النرجسية،، في حين كثفت النتائج وجود فروق دالة على مقياسي التصوير الذاتي "السيلفي" والنرجسية وفقاً لاختلاف الفئة العمرية كانت لصالح الفئه العمرية الاصغر ، بالإضافة لوجود فروق دالة على مقياسي التصوير الذاتي "السيلفي" و الشخصية النرجسية تُعزى لاختلاف عدد مرات نشر الصور الذاتية، وتعديل الصور باستخدام الفلاتر لصالح الذين ينشرون أكثر ويعدلون الصور (دائماً). الكلمات المفتاحية: التصوير الذاتي "السيلفي"، الثخصية النرجسية، اضطراب عقلي، مكة

وأعراقهم، وتعد النرجسية من المفاهيم النغسية التي حظيت باهتمام كبيرا لاى العديد من علماء النفس، وكانت بدايات استخدام هذا المصطلح منحصرة في

\section{المقدمة}

تمثل الشخصية مجموعد السمات التي توجد عند الانسان بدرجات متفاوتة تختلف باختلاف ثقافتهم 
Metamorphoses نرجس وإيكو Narcissus and Echo، نرجس هو

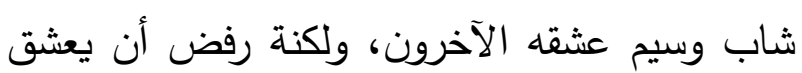

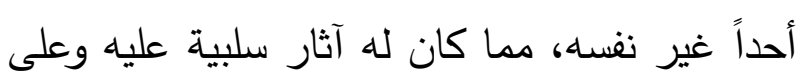

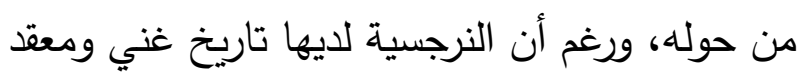
في تراث التحليل النغسي الإكلينيكي والذي بدأ بالتركيز القوي على النشاط الجنسي غير الطبيعي الذي يركز على الذات، حيث كان أول طبيب نفساني استخدم مصطلح "النرجسية" في سياق إكلينيكيا هافلوك إليس Havelock Ellis أوفيد بحالة "الإثارة الجنسية" (أي الذات كجسم جنسي

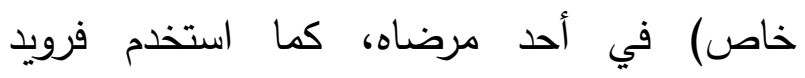

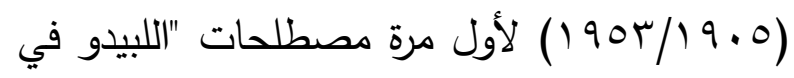
الانا"(حب الذات) و "الرغبة الجنسية النرجسية "بالتبادل في مقالاته الثلاثة حول نظرية الجالية الجنسانية

(Grenyer, 2013؛ Rosenthal, 2010) ، وفي عام 19 ، استخدمه سادجر Sadger بوصفه مفهوما في التحليل النفسي واعتبرها انحرافا خاصا

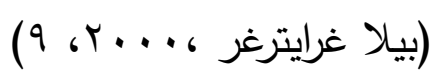
أما الإثارة الأولى والحقيقية لمفهوم النرجسية في الخطاب الفرويدي فكانت في مقالته عن " النرجسية:

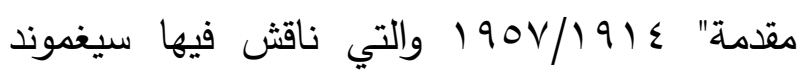
فرويد لأول مرة مفهوم النرجسية الأولية أو "غير

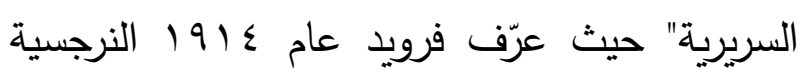
على أنها تراكم للطاقة الليبيدية التي لم يتم استثارها بعد في أي شيء خارج الذات، وفقًا لفرويد، فإن الن النا
الطابع المرضي، أما فيما بعد فقد اتضح أنها ليست

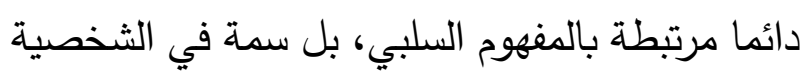
تتواجد لدى جميع الأفراد لكن بدرجات متفاوتة فتعتبر

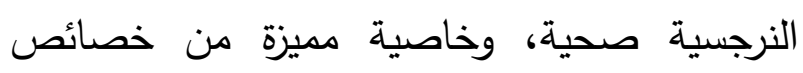
المرحلة، إلا أن هذه السمة قد تتحرف لتصبح اضطراباً في الثخصية تتميز بتعظيم الذات والتركيز عليها فقط. فالنزرجية هي "حالة نغسية تتجسد لدى الفرد بعثق الذات وتضخيمها، لدرجة تجعله يشعر أن العالم كله مسخر لذدمته سواء أكان العالم كله موضوعاً إنسانياً

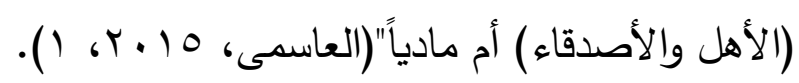

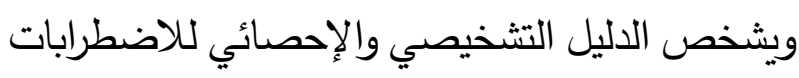

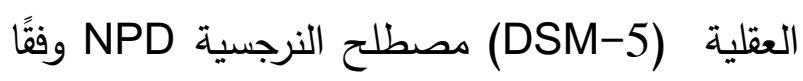

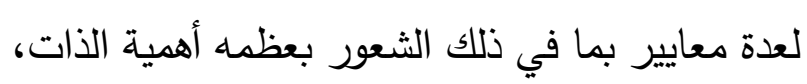
و أوهام من النجاح اللادحدود ، أو قوة ، أو تألق ، الكات

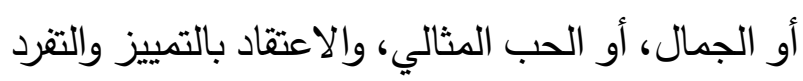

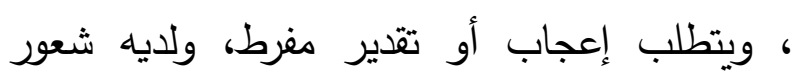

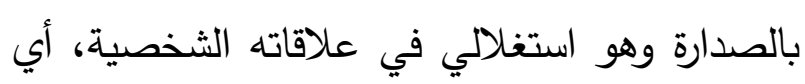
يستغل الآخرين لتحقيق مآربه، عدم التعاطف، أي أي التاني

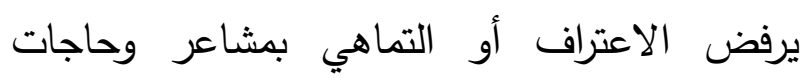
الآخرين، وغالبا ما يكون حسود أولديه الاعتقاد بأن الآخرين يحسدونه، يظهر سلوكيات أو مواقف الإنقان American Psychiatric) متغطرسة متعاليه .(Association, 2013 وقد ارتبط مصطلح النرجسية بالأسطورة الإغريقية

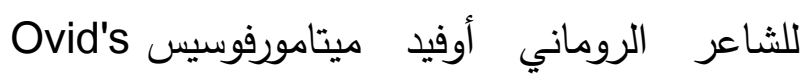


ومن سنوات بدأ مفهوم النرجسية يشمل خصائص معينة مألوفة بالشخصية وعلم النفس الاجتماعي اليوم، كان إرنست جونز $1901 / 191$ Ernest Jones أول من فسر النرجسية على أنها سمة شخصية أطلق عليها عقدة العصمة "God-complex"، ووصف الناس الذين لديهم " عقدة العصمة" بأنهم منعزلون، لا يمكن الوصول إليهج، معجبين بذاتهم، لديهح غطرسة وغرور ، وثقة مغرطة بذواتهم، ولديهم اثارة جنسية، مع أوهام القدرة المطلقة والمعرفة الكاملة، كما أنهم بحاجه إلى التفرد والثناء من الآخرين، هذا الوصف قريب بشكل ملحوظ من المفهوم الحالي لاضطراب الشخصية النرجسية 2010; .Grenyer, 2013)

واستخدم العديد من الباحثين في علم النفس الاجتماعي والشخصية المصطلحين النرجسية normal or الطبيعية أو (شبه النرجسية السريرية) subclinical narcissism الميول النرجسية غير السريرية \& Campbell, 2008; Pincus \& Lukowitsky, 2010; Zeigler-Hill, Green, Arnau, Sisemore, \& Myers, 2011) وأدت هذه الاختلافات إلى اعتقاد علماء النفس الإكلينيكي بأن النرجسية بناء مرضي أكثر من الطريقة التي ينظر بها علماء النفس بالشخصية وعلم النفس الاجتماعي. وبالتالي، تم تطوير أدوات تقييم جديدة مثل قائمه النرجسية الباثولوجي Pincus et PNI
النرجسية الأولية يمكن مقارنتها بحالة المهد بمرحلة الطفولة والمتمثلة في التمركز حول الذات وحب الذات، قبل أن يتمكن المرء التواصل مع الآخرين، ويرى فرويد أن النرجسية حاضرة في كل شخص، لكنه كان يعتقد أيضًا أن التطور الصحي "يكون بالتخلص من النرجسية الأولية"، مما يشير إلى أنه يجب التغلب عليها أثناء تطور الفرد، ونظر فرويد للنرجسية بأنها مستقرة نسبيًا وموجودة في جميع الأفراد، وإن كان بدرجات متفاوتة، كما ميز فرويد بين حب الذات المفرط من الاضطرابات السريرية وأستمر التمييز بين اضطراب الشخصية النرجسية والنرجسية كسمة شraun, Aydin, Frey شخصية وليس مرضًا نفسيًا \&Peus, 2018; Miller, Lynam, Hyatt, وإمتذ Campbell, 2017, Braun,2017). الاهتمام بالنرجسية على حد سواء بعلم النفس الاكلينيكي وبالشخصية وعلم النفس الاجتماعي ولكن كان من الصعب دمج هذه الأدبيات بسبب الاختلافات في تصورها وقياسها للنرجسية. Cain, Pincus\& Ansell, 2008; Miller \&Campbell, 2008; Pincus, Ansell, עy Pimentel, Cain Wright\&Levy.2009) يزال هنالك اختلاف كبير حول مفهوم النرجسية وتقييمها بين وداخل التخصصات المختلفة، ففي أحد المفاهيم الثائعة، يتم تعريف النرجسية كسمات Foster \& ) شخصية ويتم وصفها من حيث الأبعاد .(Campbell, 2007 
انتزاع اعجاب الاخرين بهم \& (Nevid, Rathus .Greene , 2003)

ويرى فايرستون Firestone (r ( • r). أن جيل

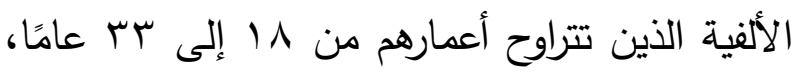

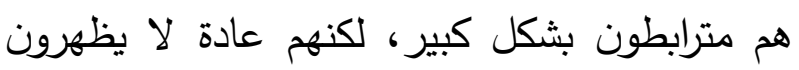
سوى القليل من الوعي أو الاهتمام بالآخرين باستثناء

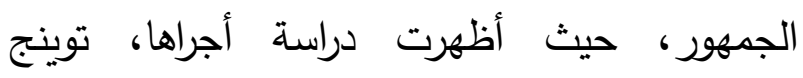
بجامعة ولاية سان دييغو، أن مستويات Twenge النرجسية قد ارتفعت بشكل مطرد خلال العقود القليلة الماضية، مما جعل جيل الألفية، أكثر أنانية واستيعابًا ذاتياً من أي جيل سابق آخر.

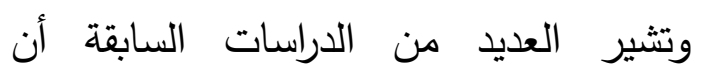
النرجسية قد تكون مرتبطة بشكل إيجابي بنشر أنواع

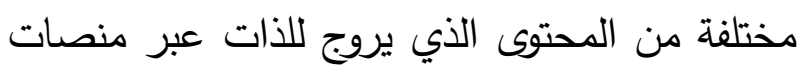

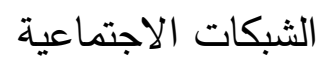
(Alloway ‘Runac ،Qureshi \& Kemp, 2014

ويُعد تصاعد الثخصية النرجسية وبروزها خطر محتمل على نمو المراهقين الثباب من حيث صحتهم العاطفية والنفسية، ويتم التعرف على النى النرجسية بالتزامن مع استخدام التواصل الشخصي كوسيلة (Panek, Nardis \& لتعزيز الذات والترويج الذات .Konrath,2013) وترى Braun (2017) أن النرجسية موجودة بحياة الجميع، وبوسائل التواصل الاجتماعي الحديثة مثل
عام 9 . . . ب التقييم الثكل الأكثر مرضية للنرجسية .(Besser\& Hill, 2011) تتميز الشخصية النرجسية بتعظيم التقدير الذاتي "العظمة"، بالاهتمام الزائد بالذات و حب لبـ الظهور فالنرجسيون يتميزون بالثدة و العصبية إذا تم عرقلة

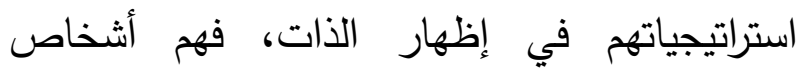
يساعدون الآخرون بهدف الظهور الذاتي (أنا الذي ساعدته حتى ينجح)، و يرتبطون بشخصيات مرموقة لهاتي

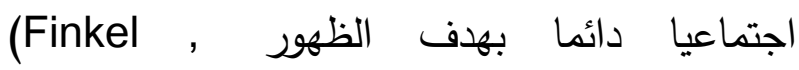
Campbell , Buffardi Kumashiro \& Rusbult,2009) الانشغال بخيالات من النجاح والقوة، والحب المثالي وتقدير التألق أو الجمال، وهم يشبهون الشخصيات الهيستيرية، والتي ربما ينجذبون نحو الاعمال التي ونماني يحصلون منها على تزلف وتملق الاخرين مثل التقليد والتمثيل أو العمل السياسي، ولديهم ميل للمبالغة في تركي انجازاتهم وقدراتهم، كما ينجحون في أعمالهم تماما لكنهم يحسدون الاخرين الذين يحققون نجاح أكبر ،

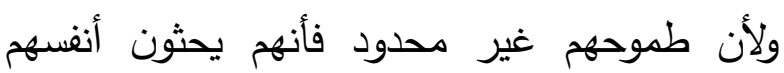
ويكرسون جهودهم للعمل بشكل متواصل، وانهم مدفعون للنجاح ليس من اجل المال وانما من أجل التملق والمداهنة تجعلهم يعكفون على النجاح، وان علاقاتهم الشخصية متوترة تجعلهم يتطفلون على بلى الاخرين لنقص تعاطفهم، وعدم اهتمامهم بالآخرين،

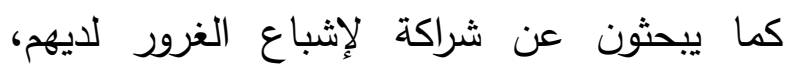

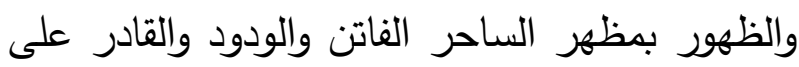


ABC ذاتية لالتقاط إصابة في شفته، ويتم تمييز الصورة الذاتية المنشورة "السيلفي" عن الصورة الذاتية هو لهوني جانب القيام بالنشر .

ويمكن إرجاع استخدام مصطلح "selfie" إلى عام ؟... عندما استخدمت شبكة مشاركة الصور الاجتماعية Flickr المصطلح "selfy" لوصف اللقطات الرقمية ذاتية الالتقاط، علاوة على ذلك، يكشف التحقيق في أصل الكلمة عن التعريف الأول الذي ورد في Urban Dictionary عام ه .. ب على أنه "صور ذاتية التقطتها الفتيات المراهقات"، ومع ذلك، فقد كان شائعًا فقط في منصات الوسائط الاجتماعية مثل و Instagram وMyspace ، اما في خارج وسائل التواصل الاجتماعي، فقد اكتسب التعبير شعبية في حوالي عام عندما تم إيقاف المشاهير للتصوير مع ب...V المعجبين الذين يصطفون بجانب المصورين الصحفيين. (2016, In Shaha \& Tewarib) ومع إطلاق iPhone ؛ المجز بكاميرا أمامية في

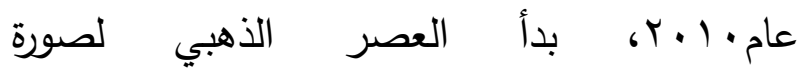
السيلفي(Bentley,2019,5). وبحلول عام Y I • r. تم استخدام "التصوير الذاتي" "selfie"على نطاق Selfie واسع عبر وسائل الإعلام الرئيسية وتم اعتمادير Oxford باعتبارها .(Dictionaries, 2013
Facebook، فمنحت الافراد فرصًا للتعبير عن الذات

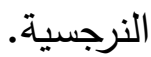
يتميز النرجسيون بالجاذبية، والظن أن جاذبيتهح واعجابهح بأنغسه وشكلهم هو الذي يشبع لئريز

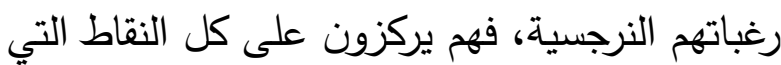
تظهرهم بأجمل وأفضل وجه Nicholas ) \&Michael , 2010 , 134) فقد أظهرت الدراسات أن الصور تحتوي إثارات تتعلق بالشخصية فقد ارتبطت النرجسية بالجاذبية والملابس البراقة والمكياج (Vazire, Naumann, Rentfrow\& ( Gosling, 2008) ، ويعتبر التقاط الصور الشخصية "السيلفي" عبارة عن موضوع فوتوغرافي يبدأ بعملية نقل الشعور الإنساني في شكل علاقة (بين المصور والتصوير ، وبين برامج الصور والتتقية، وبين

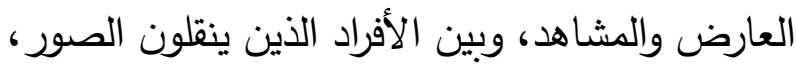

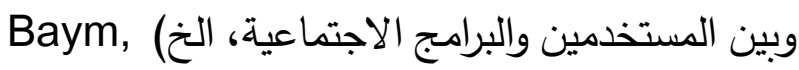
(Senft \& 2015) يمكن وصف الصورة الثخصية بأنها صورة ذاتية التقطها شخص من نفسه، باستخدام هاتف ذكي أو كاميرا ويب، والتي يتم مشاركتها كثيرًا مع الآخرين عبر وسائل التواصل الاجتماعي (Sorokowski, Sorokowska, Oleszkiewicz ، , Frackowiak, Huk, \& Pisanski, 2015) Oxford Dictionaries وفقًا لقاموس أكسفورد

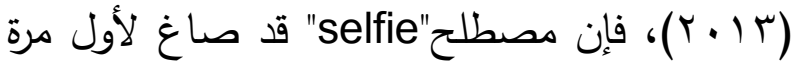

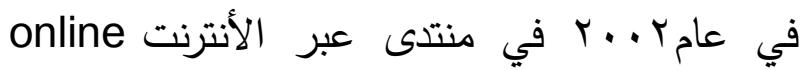


وجد باوندرز ، كوالكزيك، ستورز

Pounders,

Kowalczyk,

and

Stowers يحفز الأفراد على مشاركة صور السيلفي من أجل

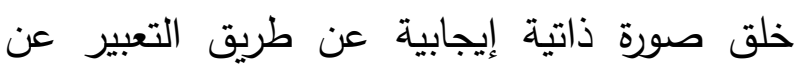
السعادة أو مظهر جسدي إيجابي.

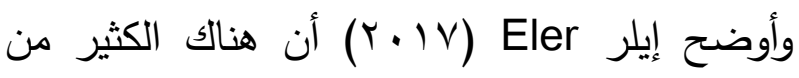
الأسباب التي تجعل الفرد يلتقط صورة شخصية وينشرها، فصور السيلفي يمكن أن تكون طريقة جيدة

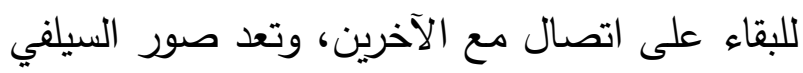

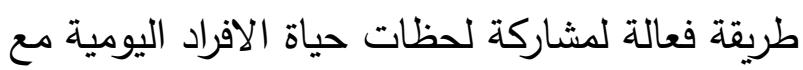
الآخرين، فهي جسر يربط بين الآخرين بطريقة ذات

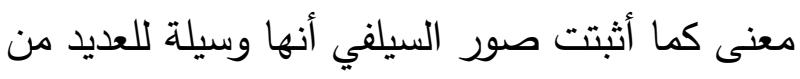
الافراد لإبراز جمالهم وحياتهم الحميمية الخاصة، كما لمانس أن وسائل التواصل الاجتماعي أداة مفيدة لتمكين الذين

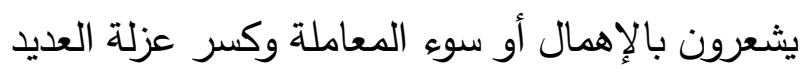
ممن يشعرون بأنهم مختلفون عن الآخرين.

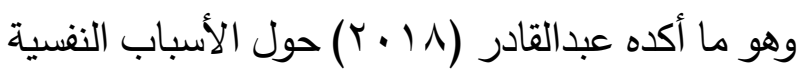
وراء هوس المستخدمين "بالسيلفي" وعملية التصوير،

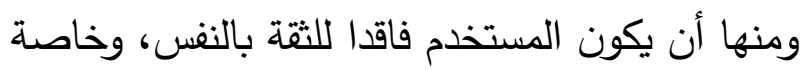
فيما يتعلق بالثخصية من جمال ومظهر ، وهو مان ينعكس في عرضة لصورة على مواقع التواصل الاجتماعي، حيث يعمد المستخدم إلى إظهار جماله بشكل يعتقد فيه أنه يمنحه القوة والثقة، خاصة إذإِ حظيت صوره بإعجاب الاصدقاء والمتابعين، فهو بذلك يكون قد لفت أنظار الآخرين، وحصل على لاعلى
لم يعُد التصوير الذاتي " السيلفي" مجرد صورة ذاتية، بل هي ظاهرة رافقت اجتياح الهواتف الذكية للحياة اليومية وانتشرت انتشارا واسعا في جميع أنحاء العالم، وباتت تشكل هوسا لدى الكثيرين من جميع الأعمار .

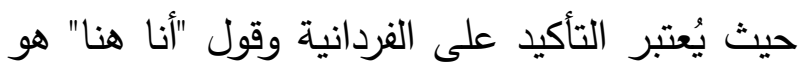
من طبيعة الإنسان. قبل أربعين ألف عام، فقد ترك البشر بصمات اليد على جدران الكهوف، تزين الجدران

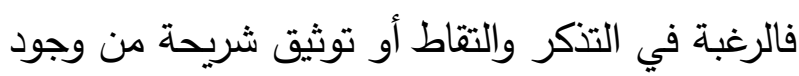
المرء أمر طبيعي (Bentley,2019). فنحن الآن نعيش بعالم مليء بالسيلفي، فيظهرون في كل مكان، سواء كان حدثاً رياضياً أو تخرجاً أو جنازة. فلدينا عصا سيلفي لالتقاط صور أفضل لأنفسنا، فينشر الافراد الصور الذاتية لزيادة حجم "الإعجابات"

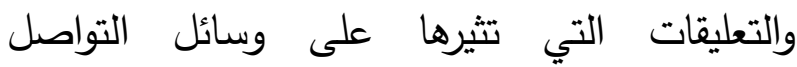

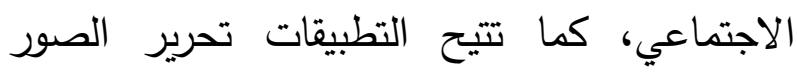
بإضافة لمسة جمالية إلى صورنا الثخصية وتحسين مظهرنا وتحريرها (Blanchette, 2017). وتُعرف الصورة الذاتية Selfie بأنها صورة ذاتية، يتم التقاطها عادةً بكاميرا أو هاتف محمول في يدك أو

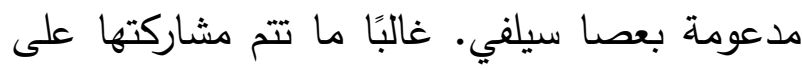

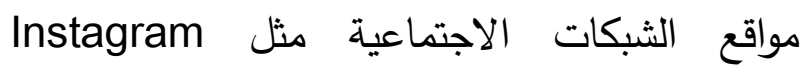
و و و و FacebookatSapp تكون جذابة وتجعلها تبدو غير رسمية (Oxford)

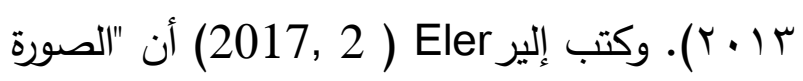
الشخصية هي مرآة ، فصورة السيلفي المشتركة هي مرآة مشتركة تعكس لحظة التقاطها ". 
في حين أظهرت الدراسات أنه يمكن للأشخاص الحكم بدقة على السمات الشخصية بناءً على الصور (Shevlin, Walker, Davies, Banyard \& Lewis,2003; Berry \& Finch-Wero, 1993 . حيث يعتبر التصوير الذاتي "السيلفي" ومشاركة الصور على منصات التواصل الاجتماعي الشهيرة مثل Facebook و Twitter واحدة من أكبر المساهمين في ارتفاع السلوك النرجسي بين جيل الألفية. ويُعرف جيل الألفية، بأولئك الذين ولدوا بين الذين

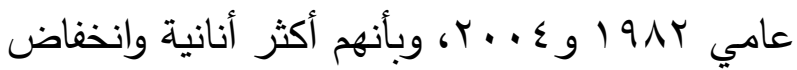
بالتعاطف مقارنة بالجيل السابق، وينشرون صورهم Pew Research ) الشخصية في كثير من الأحيان (Center, 2014; Firestone, 2012 و "السيلفى" باعتباره التقاط الهواة صوراً لأنفسهج، بواسطة هواتف ذكية (Weiser,2015). عادة، يتم تحسين صور السيلفي باستخدام "التصفية" قبل تحميلها على وسائل التواصل الاجتماعي (Hess,2015b). وتُستخدم الفلاتر للتعديل بغرض إنشاء صور أفضل ليراها الأخرين، ومن خلال تحسين الصورة، تصبح الصور الذاتية وسيلة مثالية للأشخاص لإنشاء صور (Souza, Las Casas, Flores, إيجابية لأنفسهح الإنهاء

Youn, Cha, Quercia \& Almeida,2015) وفقًا لدراسة أجراها مشروع الإنترنت والحياة الأمريكية بمركز بيو للأبحاث باستخدام استطلاع عبر الجراه

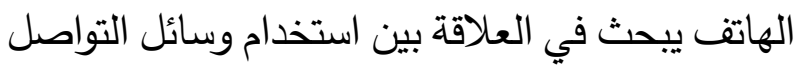
الاجتماعي والتعاطف والنرجسية وجدت أنه بالنسبة
بعض القوة النفسية لتعويض ضعف ثقته بنفسه، ومشاعر عدم القيمة والتهميش. أما من حيث اختلاف العينات بين الجنسين والمرحلة

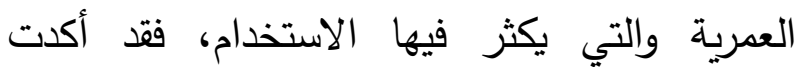
الدراسات السابقة إلى وجود فروق بين الجنسين الذكور والإناث في التصوير الذاتي "السيلفي" ومشاركتها، حيث وجد أن الإناث أكثر نشاطًا من الذكور كدراسة

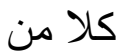
Sorokowski et al, 2015; Dhir, Pallesen, Torsheim \& Andreas sen, 2016; Sorokowska, Oleszkiewicz, Frackowiak, Pisanski, Chmiel, and Sorokowski, 2016 و بالواقع، يُعد التصوير

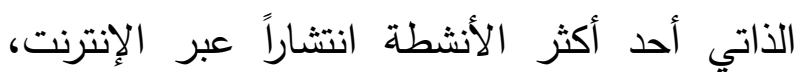
خاصة بين المراهين : Senft and Baym, 2015) Kiprin, 2013; Lenhart, Purcell, Smith, Zickuhr, 2010 ، وكذلك بالنسبة للشباب بسن الكلية. كما أظهرت دراسة حديثة في الولايات المتحدة أن ^9 ٪ من المشاركين (الذين تتراوح أعمارهم بين

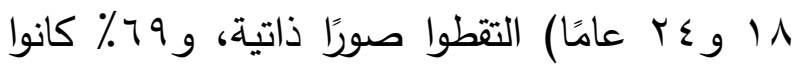
يميلون إلى مشاركة الصور الثخصية بَ إلى • r مرة يوميًا (Katz \&Crocker, 2015). كما تفيد Google من بو مليون صورة شخصية يوميًا على نماذج أجهزة . (Brandt, 2014) وحدها Android 
إلى أن نشر الصور الشخصية مفضل من قبل أولئك الذين لايهم ميول نرجسية (العظمة) أكثر .

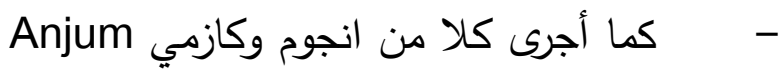
\&azmi العلاقة بين عدد من سلوكيات نشر الصور الشخصية والنرجسية واحترام الجسد، تكونت عينة الدراسة من عن بن

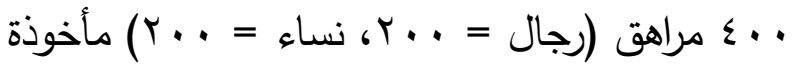
من 0 كليات بمدينة لاهور ، تم استخدام مقياس سلوك نشر الصور الثخصية وقائمه الشخصية النرجسية ومقياس تقدير الجسد لجمع البيانات. أظهرت النتائج أن عدد صور السيلفي المنشورة على الإنترنت (في الأسبوع) لله علاقة إيجابية داله بين النرجسية واحترام

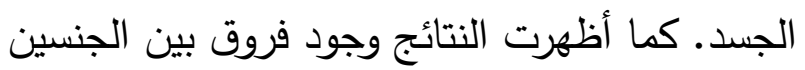
فقد كانت النساء أكثر عرضة لنشر صور سيلفي مقارنة بالرجال. بالإضافة، كان لاى النساء اللواتي ينشرن الصور الثخصية المزيد من النرجسية.

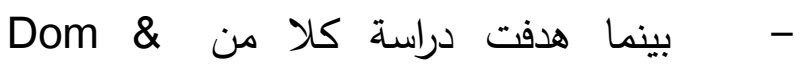
Venkatachalam شخصية الطالب الجامعي والسلوك الذي يشبه التصوير الذاتي "السيلفي" حيث استخدت الدراسة مقياس العوامل الخمسة الكبرى للشخصية النسخة Selfie- القصيرة، ومقياس الاعجاب بالسيلفي Likeing وقد بلغ إجمالي العينة ه ـ ـ من المراهقين الذين يدرسون بكليات الدراسات العليا، وأظهرت النتائج

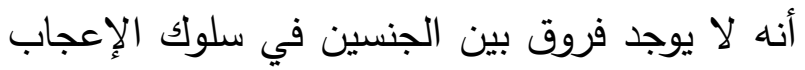
بالسيلفي. كما أظهرت وجود علاقة إيجابية كبيرة بين
لكل من الذكور والإناث، كان النشر والتمييز والتعليق

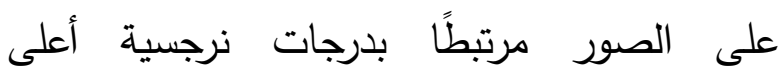
(Alloway, et al, 2014). وقد أجريت العديد من الدراسات التي تتاولت التصوير

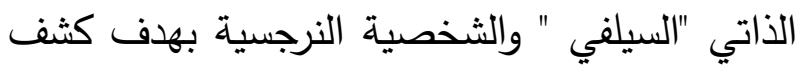
Shane- العلاقة بين المتغيرين، فقد أجرى كلا من Simpson, Obeid, Schwartz, Abi-Habib

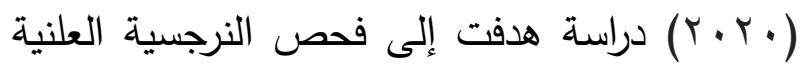
والسرية لفهم سلوكيات نشر الصور الذاتية داخل ثلاث مجتمعات جغرافية، بحثت الدراسة ما إذا كان يمكن توقع النشر الذاتي بحسب درجه النرجسية والديموغرافيا وعضوية المجتمع. (أي الثقافة) والتركيبة السكانية. قام الباحثون بقياس السمات النرجسية وسلوك النشر

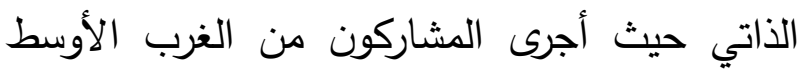
للولايات المتحدة بلغ ؛9 1، في حين بلغ المشاركين من شمال شرق الولايات المتحدة ؟YVr، ومن لبنان • بr استطلاعًا عبر الإنترنت، تم توقع تكرار نشر الصور الذاتية حسب الجنس والمجتمع الجغرافي ونرجسية العظمة، أظهرت النتائج وجود علاقة بين

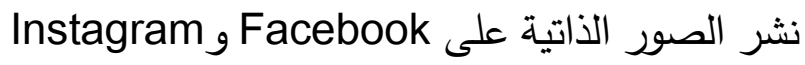
والنرجسية (نرجسية العظمة)ومع ذلك، لـ ترتبط أنواع أخرى من النرجسية -نرجسية القيادة، نرجسية الجدارة، والنرجسية الضعيفة -مع نشر الصور الثخصية "

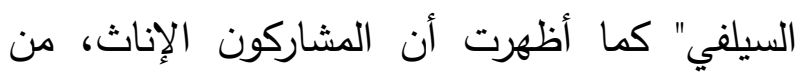
الشمال الشرقي بالولايات المتحدة والذي لديهخ نرجسية عالية، نشروا صورًا ذاتية بشكل متكرر، تشير النتائج 
النساء إلى النشر وتقديم أنفسهن بشكل أكبر كجزء من مجموعة اجتماعية

Sukhdeep, Maheswarisk \& Sharma هدفت إلى فحص سمات الشخصية النرجسية وسلوك التقاط الصور الذاتية بين طلاب الجامعات في البنجاب، بالهند. استخدمت الدراسة مسح لتتييم السمات النرجسية وسلوك التقاط الصور الذاتية في

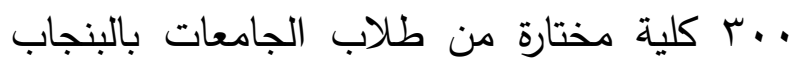
باستخدام ورقة البيانات الديموغرافية الاجتماعية ومقياس الثخصية النرجسية (NPI 16) وأظهرت النتائج أن درجه النرجسية لطلاب الكلية في مستوى معتدل. كما أظهرت النتائج وجود علاقة كبيره بين سمات النرجسية مع عدد الصور الثخصية، وتفضيل التقاط الصور الثخصية، وتحرير الصور الثخصية

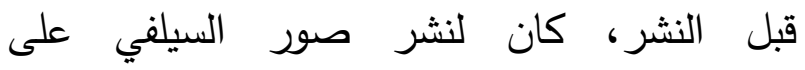
Facebook وخلصت الدراسة إلى أن غالبية طلاب الجامعات

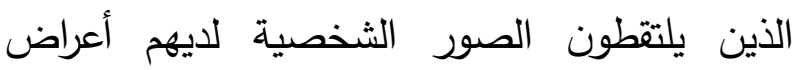
نرجسية. - مام Hernowo \&Mashoedi درجة -

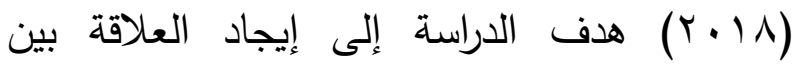

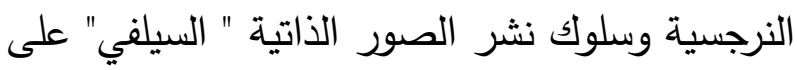
Instagram

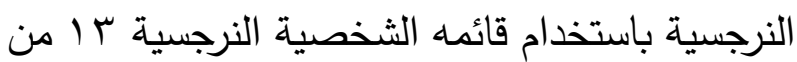
Gentile et al
التفاني أو (يقظه الضمير) مع أبعاد الإعجاب بالسيلفي والنرجسية. Biolcati \& Passini التنبؤات المختلفة للنرجسية وتقدير الذات من خلال دوافع سلوكيات نشر الصور الذاتية "السيلفي "مع ماتير

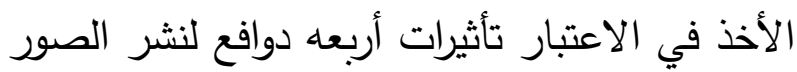

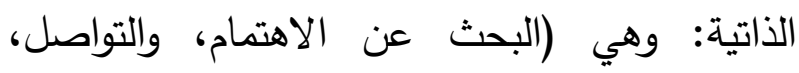

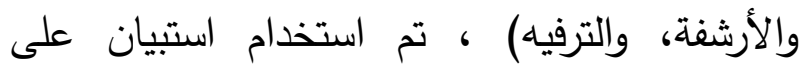

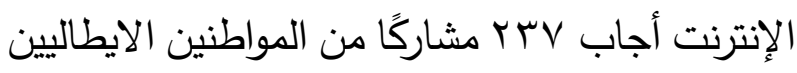

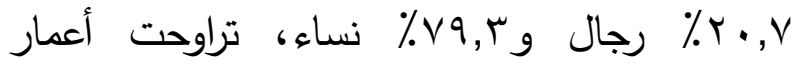
المشاركين من \1 إلى •ـ سنة أظهرت النتائج أن دوافع نشر الصور الشخصية والنرجسية وتقدير الذات ترتبط بشكل مختلف بالتكرار frequencies اعتمادًا على نوع الصورة الشخصية المنشورة على الإنترنت (صور شخصية خاصة؛ صور شخصية جماعية صور شخصية مع الثريك). علاوة على ذلك، يُظهر جنهر

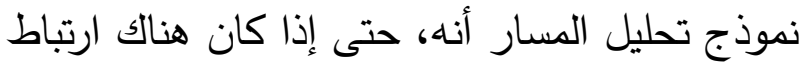
إيجابي بينهما، فإن تقدير الذات والنرجسية لهما دوافع مختلفة وراء استخدام صور السيلفي. على وجه

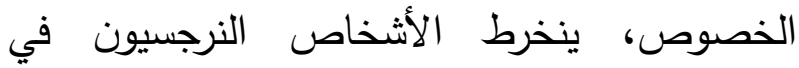
سلوكيات نشر الصور الثخصية بسبب لفت انتباه الآخرين والحاجة إلى الهروب من الملل، كما أظهرت

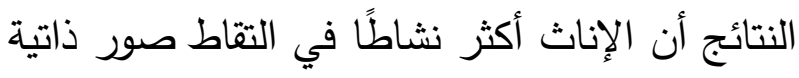
جماعية، في حين لم تظهر أي اختلافات بين الجنسين في صور السيلفي الخاصة ومع الشريك. بمعنى تميل 
ينشرون صورهم الذاتية بانتظام داخل كل مجموعة، كما

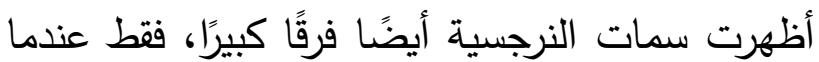
تمت مقارنة الذكور من كلا المجموعتين مرة أخرى لصالح طلاب السنة الأولى من كليه الطب. Bunker \& Gwalani الجسد وسلوك التقاط الصور" السيلفي" بين المراهقين والثباب Teens and Adolescents لإكتشاف العلاقة المتبادلة بين النرجسية وتقدير الجسد استخدت الدراسة الميدانية النرجسية وتقدير الجسد للمراهقين والثباب الذين يأخذون r-ه صور شخصية في اليوم، ويتم اختيارهم عن قصد. أجريت الدراسة

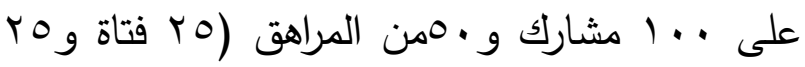

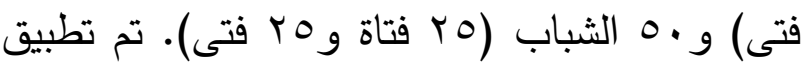
مقياس تقبل أو تقدير الجسد من إعداد م

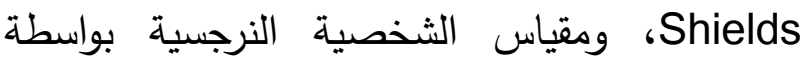
Raskin \& Hall بالنرجسية وجود فروق بين المراهقين والثباب الذين

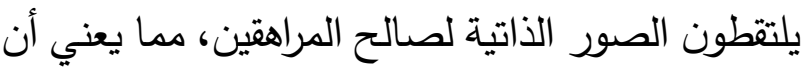

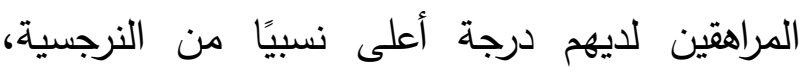
وكثفت بيانات لقياس درجة النرجسية بين سلوك دركين

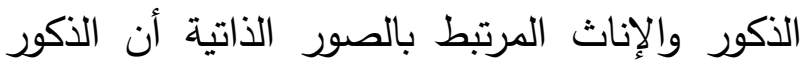

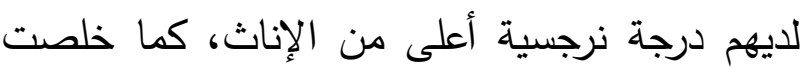
الدراسة إلى أن كلا من النرجسية واحترام الجسد يتنبأ بسلوك سيلفي للمشاركين.
الثخصية باستخدام تكرار نشر الصور الذاتية في

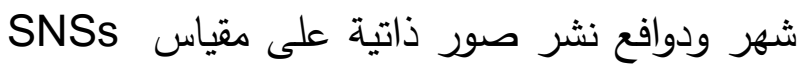
مung et al من SuPS) إلى اللغة الإندونيسية، أُجرى هذا البحث على بـ

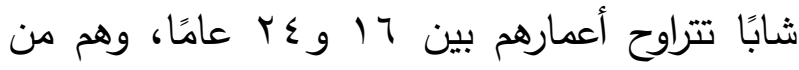
مستخدمي Instagram النشطين في إندونيسيا. أظهرت النتائج وجود ارتباط كبير بين النرجسية وسلوك النشر الذاتي، حيث تكون الدرجة الأعلى في النرجسية، كلما التقطت صور شخصية أكثر . Dutta, Sharma, في حين اجرى كلا من سله سله Dikshit, Shah, Sonavane, Bharati, Sonavane \& Desousa هدفت إلى استكثاف المواقف تجاه التقاط صور السيلفي وعلاقتها بصورة الجسم والنرجسية لدى طلاب كلية الطب. لدراسة مستعرضة وكان لديها مجموعتان

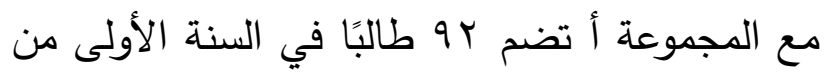
الطب ومجموعة ب r • ا طلاب دراسات عليا (PG) من تخصصات مختلفة، تمت مقابلتهم بجلسة واحدة باستخدام مقياس الموقف تجاه أخذ الصورة الذاتية، وقبول صورة الجسم واستبيان العمل Body (BIAAQ) باستخاه Image-Acceptance and Action Questionnaire أظهرت النتائج وجود اتجاه إيجابي وقوي تجاه التقاط

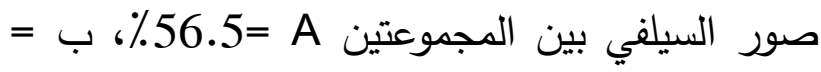

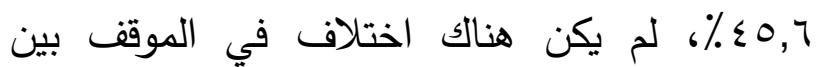
المجموعتين، أو اختلاف في الجنس بين أولئك الذين 
شخصية وأسئلة مفتوحة ومغلقة حول سلوك نشر

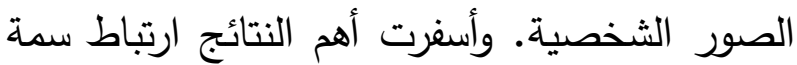
Dark Triad الذاتية "السيلفي"، حيث ينشر الرجال النرجسيون صورًا ذاتية أكثر بكثير من النساء النرجسيات، أظهر كل من النرجسية المنخفضة والتعلق القلق ينبئان بزيادة

$$
\text { نشر الصور الشخصية. }
$$

أوضحت دراسة كلا من McCain, Borg,

Rothenberg., Churillo , Weiler \& Campbell. ودوافع نشر والتصوير الذاتي "السيلفي" وأنماط النرجسية السوية والمرضية يشمل الثالوث المظلم لسمات الشيكوباتية، الميكيافيلية، تقدير الذات) وتوصلت الدراسة إلى النتائج التالية :توجد علاقة ارتباطية موجبة بين النرجسية وزيادة نشر الصور الذاتية "السيلفي"، - كما توجد علاقة ارتباطية موجبة بين النرجسية وزيادة التقاط الصور أيضا- كما توجد علاقة ارتباطية موجبة بين النرجسية ودوافع التقاط وعرض الذات المبالغ فيه على مواقع التواصل الاجتماعي.- كما لا توجد علاقه بين النرجسية المرضية والتصوير الذاتي

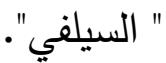

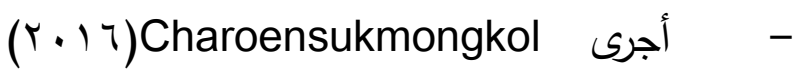
دراسة تكشف عن الخصائص الثخصية المرتبطة بإعجاب السيلفي هدفت الدراسة الكثف عن أربع خصائص شخصية قد تفسر سبب رغبة بعض الأفراد
دراسة نزار (1/ • ץ) ادمان الصور الذاتية "

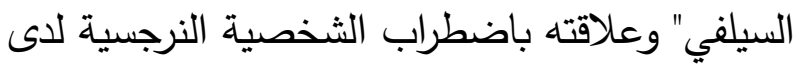
طلبه الجامعة المستصرية، هدفت الدراسة الى التعرف عن العلاقة بين ادمان الصور الذاتية "السيلفي" واضطراب الثخصية النرجسية ودلاله الفروق بالعلاقة بين ادمان السيلفي واضطراب الشخصية النرجسية لاى طلبه الجامعة المستتصرية، استخدمت الدراسة مقياس ادمان الصور الذاتية السيلفي ومقياس الشخصية النرجسية، وتكونت العينة من ( . . ع) طالبا وتوصلت النتائج الى وجود علاقه ارتباطيه داله إحصائيا بين ادمان الصور الذاتية " السيلفي" واضطراب الشخصية النرجسية، كما أظهرت النتائج عدم وجود فروق بين الجنسين في إدمان الصور الذاتية" السيلفي" كذلك أظهرت النتائج عدم وجود فروق بين الجنسين في اضطراب الشخصية النرجسية. Nancy (Y.lV) Adler وسائل التواصل الاجتماعي وعلاقتها بالنرجسية المرضية والنرجسية شبه السريرية، والثالوث المظلم the Dark Triad النفسي"، والاندفاع، والتعلق، وحساسية الرفض، والأداء التأملي كمتنبئين محتملين لنشر الصور الذاتية على وسائل التواصل الاجتماعي. كما تم طرح عدد من الأسئلة مفتوحة بهدف الحصول على الدوافع وراء نشر صور شخصية، تكونت العينة من 99؛ مشاركًا أكملوا استطلاع عبر الإنترنت يتكون من مقاييس 
النرجسية وأوجهها ونثر صور السيلفى لا تعتمد على العمر ـ ومع ذللك، ظهر جانب القيادة / السلطة الأكثر

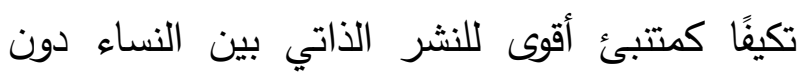
الرجال، في حين تتبأ جانب الاستحقاق /الاستغلال السيئ النشر الذاتي بين الرجال دون النساء.

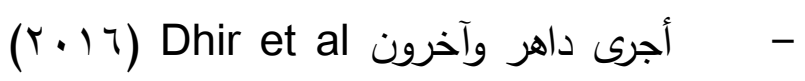

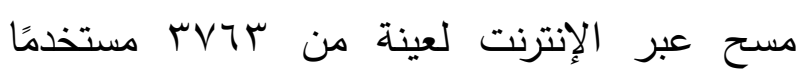

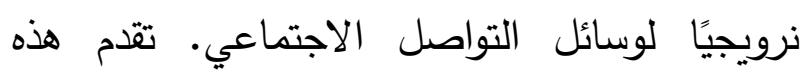
الدراسة أول دليل تجريبي حول كيفية اختلاف

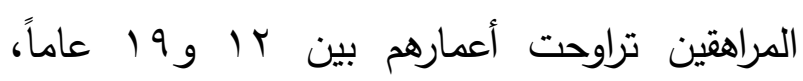

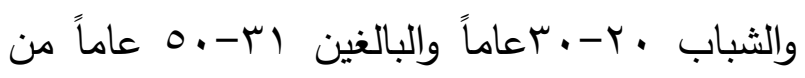
حيث سلوك الصور الشخصية. كانت الإناث أكثر في التصوير الذاتي" السيلفي" الخاصه والجماعية، وفي نشر الصور الشخصية، واقتصاص الصور، واستخدام الفلاتر الفوتوغرافية مقارنة بالذكور • تم العثور على الفى المراهين أكثر عرضة من الثباب للتصوير الذاتي"السيلفي" الثخصية الخاصة بهم أو جماعية،

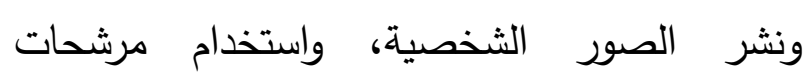
فوتوغرافية. وبالمثل، كان الثباب أكثر عرضة للتصوير الذاتي" سيلفي" خاصة بهم ومجموعات، ونان ونشر الصور وتعديلها أكثر من كبار السن. كان التأثير التتبئي للعمر بين النساء أقوى منه بين الرجال فيما يتعلق بسلوك التقاط الصور الشخصية ونشرها وتحريرها.

Sorokowski, Sorokowska, Oleszkiewicz,
في التصوير الذاتي "السيلفي" أكثر من الآخرين. وهي

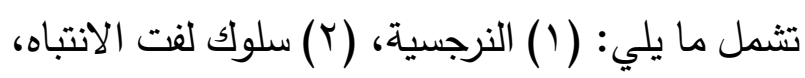

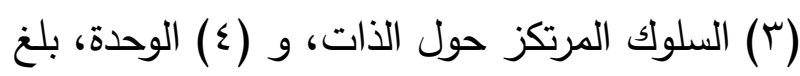

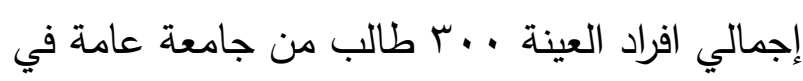
تايلاند، أظهر تحليل الانحدار أن درجة الإعجاب

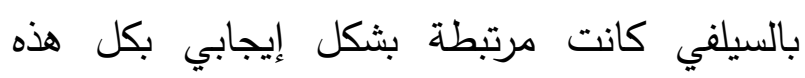
الخصائص، كما تثير النتائج الإجمالية إلى أنه على لئى الرغم من أن الصور الثخصية توفر الفرصة للأفراد

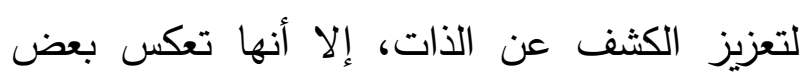
السلوك غير الصحي من جانبهم.

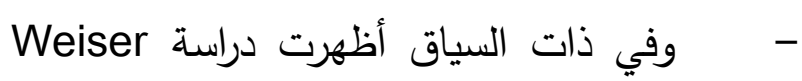

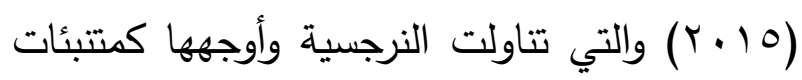
بتكرار نشر الصور الذاتية، "السيلفي" والتي هدفت لمعرفه العلاقة بين النرجسية، وتكرار نشر صور السيلفي على مواقع التواصل الاجتماعي. بالإضافة إلى ذلك، تم استكثاف العلاقة بين نشر صور السيلفي وثلاثة جوانب من النرجسية والارتباط بين نشر صور السيلفي وثلاثة جوانب من النرجسية (أي، القيادة / السلطة، العظمة / الاستعراض Grandiose Exhibitionism facets، الاستحقاق / الاستغلال)

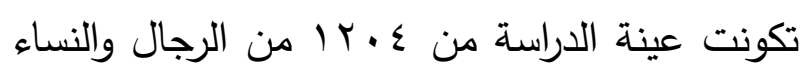
الذين أكملوا استطلاع عبر الإنترنت. أظهرت النتائج

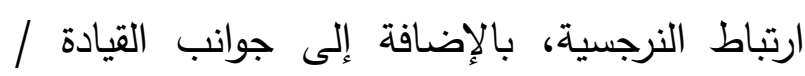
السلطة، العظمة /الاستعراض، ولكن ليس الاستحقاق

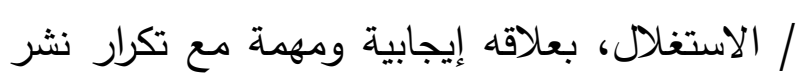

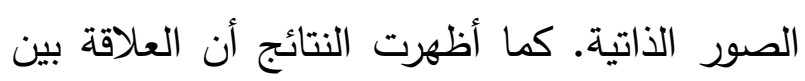


لتبادل الصور الاجتماعية مثل (Instagram). كان

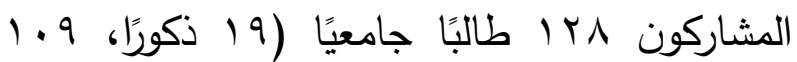
إناث) تتراوح أعمارهم بين 1 ا إلى بــ عامعًا تم ترميز صور السيلفي وفقًا لتكرارها بالنسبة إلى مشاركات المشاركين غير الشخصية وموضوعاتهم (أي المظهر الجسدي، النشاط / الحدث / الموقع، الانتماء إلى الى

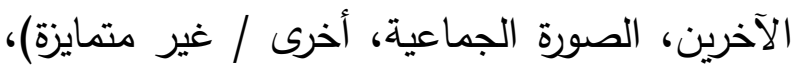
العلاقات المفترضة للنرجسية وتقدير الذات مع نشر الهرئ الصور الشخصية المستقلة لم تكن كبيرة. ومع ذلك، كانت هناك علاقة كبيرة بين بعض أبعاد النرجسية وفئات معينة من صور السيلفي (على سبيل المثال، نرجسية ضعيفة مع صور شخصية للمظهر الجسدي).

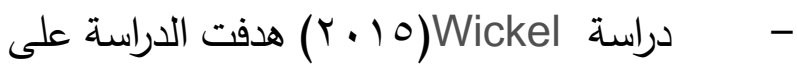
الكثف عن سبب سلوك التقاط صور "السيلفي" ونشرها على الإنترنت كعامل يؤدي إلى زيادة في السلوكيات

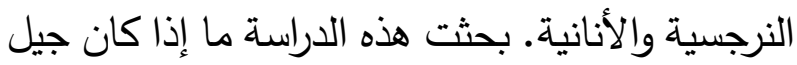
الألفية يعتقد أن ظاهرة السيلفي تسهم في ارتفاع

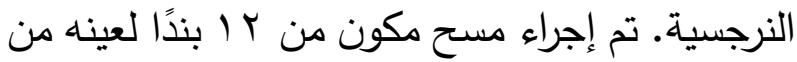
بو مشاركة من الكليات. سأل سؤال واحد مفتوح النهاية وهو "ما إذا كان المستجيبون وجدوا أن سلوكهح في نشر صور شخصية نرجسية". وجدت هذه الدراسة أن هo ٪ من المشاركين اتفقوا على أن نشر صور السيلفي في منصات الثبكات الاجتماعية المختلفة شجع نرجسيتهم وسلوكهم الأناني.

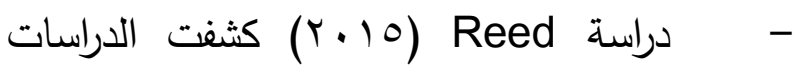
الحديثة عن وجود علاقة بين الصور التي تعزز الذات
Frackowiak, Huk, \& Pisanski مجمعة من ب9 Y ا رجل وامرأة ، تم إختبار التتبؤ بأن الأفراد الذين يحصلون على درجات عالية في أربعة

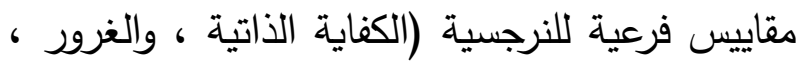
والقيادة ، وطلب الإعجاب) سيكونون أكثر عرضة ، لهنية

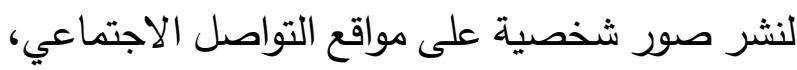
مواقع إعلامية أكثر من الأفراد الذين يظهرون نرجسية منخفضة، تم فحص ثلاث فئات من صور السيلفي:

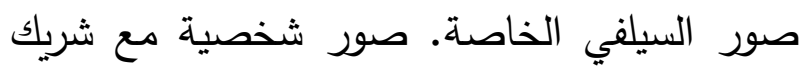

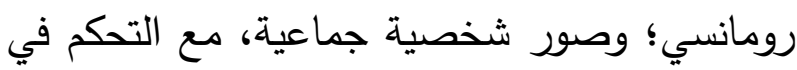
الصور غير ذاتية، نشرت النساء صور سيلفي من

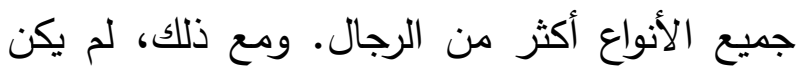

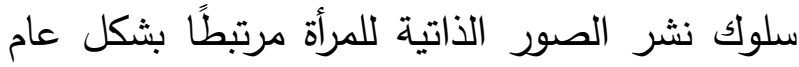
بنتائج النرجسية. على النقيض من ذلك، فإن النتائج النرجسية الإجمالية للرجال تتبأت بشكل إيجابي بنشر لبن لبن صور شخصية وصور ذاتية مع شريك وصور شخصية جماعية. علاوة على ذلك، فإن درجات الغرور والقيادة وطلب الإعجاب للرجال تتبأت بشكل مستقل بنشر نوع واحد أو أكثر من الصور الذاتية.

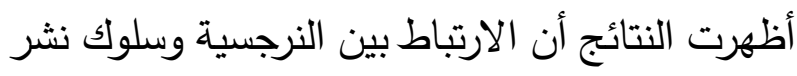
الصور الشخصية ضعيف نسبيًا بين النساء مقارنة

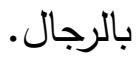

Barry, Doucette, Loflin, دراسة $(r+I V)$ Rivera-Hudson, \& Herrington. تناولت الدراسة العلاقة بين النرجسية وتقدير الذات مع نشر الصور الذاتية "السيلفي" على موقع مشهور 


$$
\text { مريم حميد أحمد اللحياني }
$$

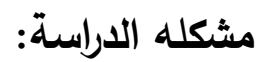

يشهد المجتمع السعودي تحولات ثقافية واجتماعية عديده، ساهمت في انتثار الكثير من المظاهر التي أثرت على شخصية الافراد، ولعل من أكثر الجوانب السلبية التي نلمسها اليوم هي المبالغة التئ في إظهار الذات، خاصة مع التقدم التقني وظهور

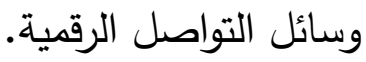

فقد زادت شعبية التصوير الذاتي "السيلفي" على مواقع التواصل مع ظهور شبكات التواصل الاجتماعي من (السناب والتيك توك والفيس بوك موكي وتوتير والواتس اب والانستجرام). كما حظي نشر التصوير الذاتي باهتمام كبير من الصحف وبالمجال

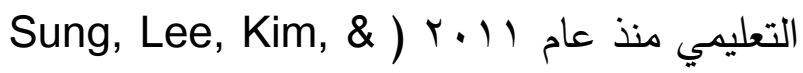
Choi,2016). فقد أشارت العديد من الدراسات وجود

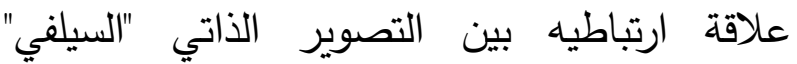
والنرجسية. وبالتحديد، تم ربطها بعدد أكبر من الصور الذاتية المنشورة على Fox \& Rooney, SNSs) 2015; McCain et al, 2016; Weiser,

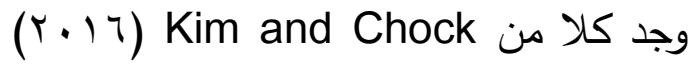

أن النرجسية قد تكون متتبنًا قويًا بسلوك نشر الصور

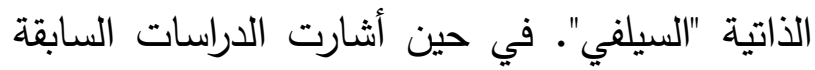
Dhir et al, 2016; Sorokowski et ) (al.,2016) إلى أن الإناث أكثر نشاطًا في التصوير

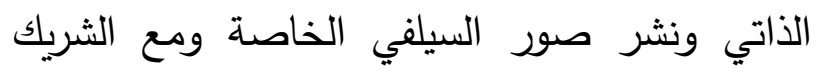
والصور الجماعية مقارنة بمستخدي الثبكات
على وسائل التواصل الاجتماعي ومستويات مرتفعة من النرجسية. كما هدفت الدراسة لمعرفه العلاقة بين النرجسية واستخدام وسائل التواصل الاجتماعي من خلال تحديد نسبة الصور الشخصية "السيلفي: التي ينشرها الأفراد على Instagram والنرجسية بين جيل تلبه الألفية. تم قياس نسبة الصور التي كانت صورًا ذاتية بطريقتين: في الأسابيع الأربعة الماضية لنشر الصورة

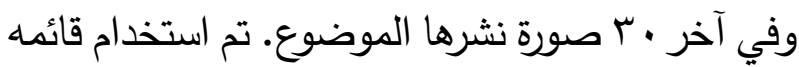

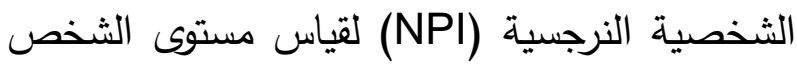
من النرجسية. كثفت تحليلات الارتباط أنه لم يتم NPI العثور على أي ارتباطات بين درجة النرجسية ونسبة الصور الشخصية المنشورة بين إجمالي مجموع الموضوعات، بينما وجدت علاقة ارتباطيه بين الأثخاص الذين قاموا بنشر صور ذاتية والنرجسية.

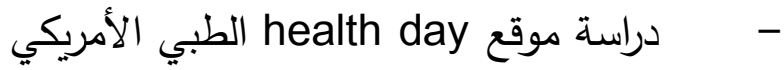
التي قادتها كلا من Fox \& Rooney (10) (10) بجامعة Ohio Fox ، الأمريكية، والتي كثفت ارتباط هذا النوع من سلوك التصوير بالنرجسية، وهو الاهتمام الزائد بالنفس، وقد شملت الدراسة 800 من الرجال تتراوح أعمارهم بين 18 و 40سنة ولانة ملأوا خلالها استطلاعاً على الإنترنت عن أنشطتهم في الصور التي ينشرونها على صفحات مواقع التواصل الاصليط الاجتماعي، بالإضافة إلى اختبارات تتييمية أخرى لهن للشخصية، وكثفت ارتباط كثرة صور" السيلفى "لاجئل

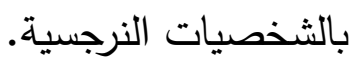


"السيلفي" أصبح ظاهرة حديثة إلى حد ما، وهي شكلاً واسعاً من أشكال التعبير عن الذات، ولحاجتنا لمعرفة

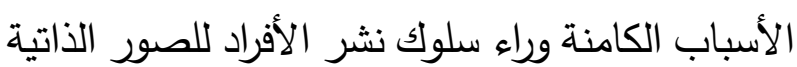
"السيلفي" والتي لازالت غير مفهومة، ولندرة الدراسات

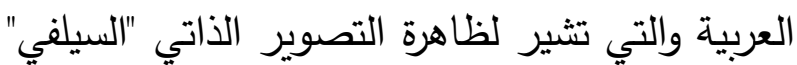

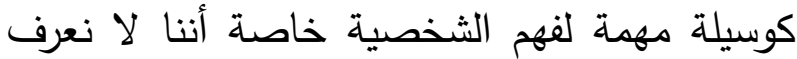
سوى القليل عما يعكسه السيلفي من شخصيات للأفراد

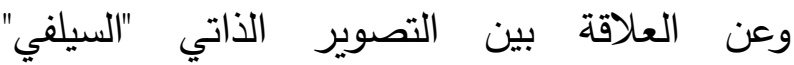
والثخصية، وهل يمكن التتبؤ بالشخصية النرجسية بناءً على نشر صورهم الشخصية؟ وتأسيسا على ما سبق جاءت الدراسة الحالية والتي تناولت ظاهره التصوير الذاتي "السيلفي" كمنبئ بالثخصية النرجسية حيث تحاول الإجابة عن الأسئلة التالية: س / ما مستوى انتشار التصوير الذاتي "السيلفي" لاى معلمي وطلبة المرحلة الثانوية بمدينة مكة

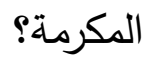
س ץ/ ما مستوى النرجسية لاى معلمي وطلبة المرحلة الثانوية بمدينة مكة المكرمة؟ س//هل توجد علاقة ارتباطية دالة إحصائياً بين مستوى انتشار التصوير الذاتي "السيلفي" والثخصية النرجسية لدى معلمي وطلبة المرحلة الثانوية بمدينة

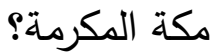
س ع / هل يمكن التنبؤ بالثخصية النرجسية من خلال مستوى انتشار التصوير الذاتي "السيلفي" لذى معلمي وطلبة المرحلة الثانوية بمدينة مكة المكرمة؟
الاجتماعية الذكور . كما أظهرت نتائج الدراسات أن النرجسية ترتبط بشكل إيجابي مع عدد تحميل أو نشر الصور عبر الإنترنت وكذلك الميل إلى الانشغال Barry بسلوكيات التحرير قبل تحميل الصور كدراسة et al, 2017; Ong, Ang, Ho, Lim, Goh, Lee, \& Chua, 2011; Ryan \& Xenos, 2011; Sung et al, 2016; Mehdizadeh, 2010 ، وغالبًا ما يلتقط أولئك الذين سجلوا درجات عالية في النرجسية صورًا لأنفسهر وينشرونها على

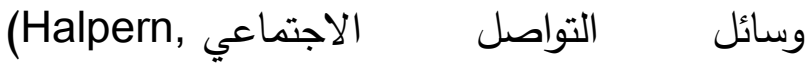
Valenzuela \& Katz,2016 ; Lee \& Sung,2016; Sorokowski et al, 2015; Sung et al, 2016) ومن الأبحاث حول عرض الذات عبر الإنترنت، أظهرت النتائج أن النساء أكثر بالتصوير الذاتي "السيلفي" وعرضها من فئة الرجال

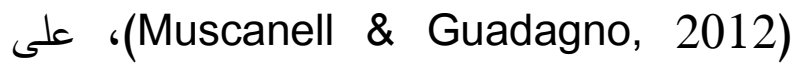
Fox \& الرغم من هذه النتائج، إلا أن دراسة Rooney

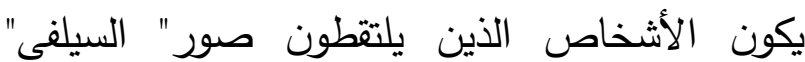
وينشرونها بكثرة على الإنترنت يعانون من المشاكل والاضطرابات النفسية، لكنها بعد انتثارها اليوم أصبحت نوعا من السلوك الثائع والطبيعي. وهو ما أكده Weiser (2015) والذي يرى أن مشاركة المعلومات على وسائل التواصل الاجتماعي

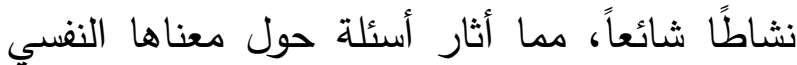
ودوافعها ذات الصلة. خاصه أن التصوير الذاتي 


$$
\text { مريم حميد أحمد اللحياني }
$$

1-ندرة الدراسات العربية التي تناولت موضوع التصوير الذاتي "السيلفي" وعلاقته بالشخصية النرجسية بصفتها موضوعات حيوية في مجال الثخصية وعلم النفس بله الاجتماعي. r-تركز الدراسة على التصوير الذاتي "السيلفي " كمنبئ

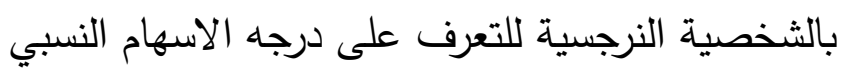
بها مما يكشف لنا واقع السيلفي ودورة بالثخصية. أما الاهمية العملية فتكمن في: ا - امكانية الاستفادة من ممارسة التصوير الذاتي "السيلفي" كوسيلة تواصلية تعليمية تعمل على تكوين علاقات إيجابية بين المعلمين والطلبة، ومن ثم خلق جو مدرسي يسوده الالفة والمحبة. r- بساهم البحث الحالي بيناء برامج نفسية إرشادية تعمل على تتمية الشخصية النرجسية المتكيفة والتخفيف من صورها المرضية لكل من لن

$$
\text { الطالب والمعلم. }
$$

r- - تقتح الدراسة الحالية آفاقًا كثيرة للمسؤولين بوزارة التربية والتعليم لاتخاذ الإجراءات والتدابير الوقائية فيما يتعلق بدور التصوير الذاتي السيلفي

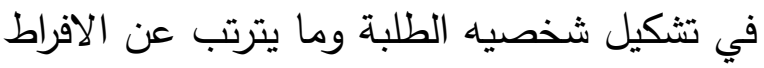
الناجمة عن استخدام هذه التقنية. ع- يمكن الإفادة من نتائج هذا البحث من قبل المرشدين النفسيين من خلال الوقوف على واقع لهن استخدام الطلبة للتصوير الذاتي "السيلفي "بهدف تقديم إرشادات توعوية تُعزز الاتجاهات الإيجابية لاى الطلبة حول الاستخدام الأمثل لها.
س0/ هل توجد فروق ذات دلالة إحصائية بين

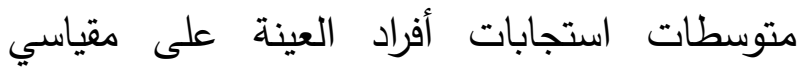
التصوير الذاتي "السيلفي" والثخصية النرجسية لدى معلمي وطلبة المرحلة الثانوية بمدينة مكة المكرمة تعزى لاختلاف: (العمل، الجنس، العمر، عدد مرات نشر الصور ، عدد مرات تعديل الصور)؟ أهداف الدراسة: هدف البحث الحالي الى الإجابة

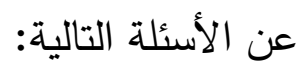
- الكثف عن مستوى انتشار التصوير الذاتي السيلفي لاى معلمي وطلبة المرحلة الثانوية بمدينة مكة

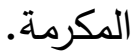
- الكثف عن مستوى انتشار الثخصية النرجسية لدى معلمي وطلبة المرحلة الثانوية بمدينة مكة المكرمة. - معرفه العلاقة بين التصوير الذاتي السيلفي والثخصية النرجسية لدى معلمي وطلبة المرحلة الثانوية بمدينة مكة المكرمة. - التتبؤ بالثخصية النرجسية من خلاد التصوير الذاتي السيلفي لدى معلمي وطلبة المرحلة الثانوية

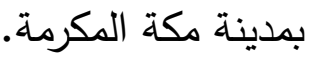
- الكثف عن الفروق ذات دلالة إحصائية في التصوير الذاتي والثخصية النرجسية لاى معلمي وطلبة المرحلة الثانوية بمدينة مكة المكرمة؟ تعزى لمتغير (العمل -الجنس -العمر - عدد مرات نشر الصور -عدد مرات تحرير الصورة). أهمية الدراسة: تبرز الاهمية النظرية للدراسة بالتالي: 
ويعرف بشكل إجرائي في هذه الدراسة بأنه " الدرجة التي يحصل عليها المفحوصين على مقياس التصوير

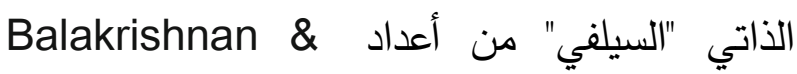
Griffiths عرف (2013, 5-DSM) النرجسية "نمط بالارسة واسع الانتشار من إحساس العظمة، والحاجة الى الأعجاب، والافتقار الى التعاطف، والإحساس التاس بالأولوية، والاستقلالية في العلاقات مع الآخرين، و والإحسان اظهار سلوكيات متعجرفة أو مبتكرة، وانشغال بالخيالات المتعدقة بالنجاح أو القوة أو الألمعية أو أو الجمال أو الحب المثالي غير المحدود، واعتقاد الثرد

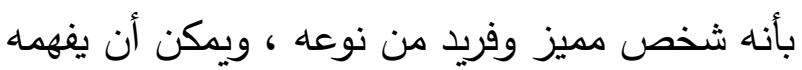
فقط أشخاص مميزون، أو ذوو مكانة اجتماعية عالية، أو يجب أن يرتبط بهم، فضلا عن أنه يحسد الآخرين،

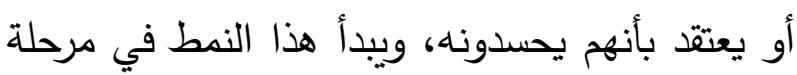
الرشد المبكر، ويظهر في مواقف مختلفة، ويعد الثخص مصابا بهذا الاضطراب إذا ما توافرت فيه خمسة مظاهر (أعراض) أو أكثر من هذه المظاهر

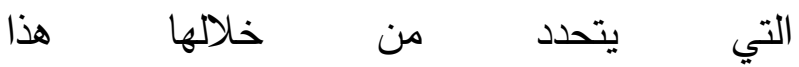
الاضطراب"(APA, 2013, 661). الطريقة اجراءات الاراسة: فيما يلي توضيح المنهج المتبع، وعينة الدراسة

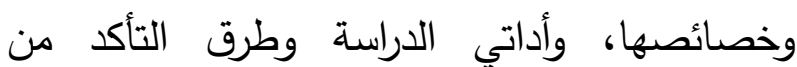

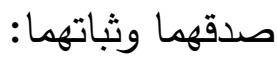

محددات الاراسة اقتصرت الدراسة على معلمي ومعلمات وطلاب وطالبات المرحلة الثانوية بالمدارس الثانوية بمكة

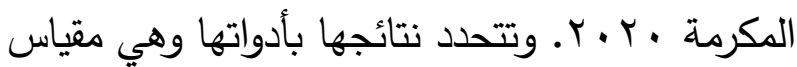
the Selfitis Behavior "التصوير الذاتي" السيلفي ومقياس النرجسية النسخة Scale (SBS). القصير (NPI-16)، وبالاستجابة على هذه المقاييس من أفراد عينه الدراسة. مصطلحات الاراسة الصورة الذاتية "السيلفي "Selfie"عرّقت قواميس

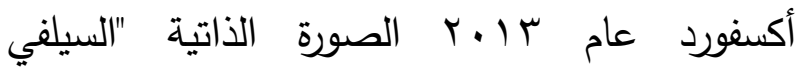
"عelfie" "

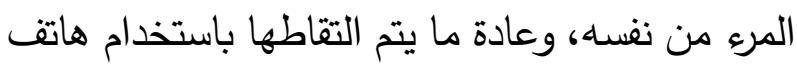
ذكي أو كاميرا ويب ومشاركتها عبر وسائل التواصل ونل فئل

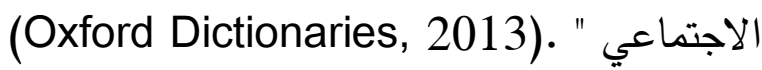
أكدت جمعية الطب النفي الأمريكية (APA) عقلي، وقد أطلقوا عليه اسم إدمان الفرد على التصوير الذاتي " سيلفي" selfitis لأن هذا الاضطراب العقلي is an inflammation of لأجيج في الأني one's ego. كما عرّف Y B. Balakrishnan \& Griffiths ع) صور السيلفي على أنها "الرغبة القهرية في التقاط

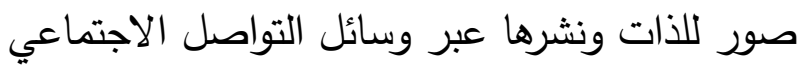
كوسيلة للتعويض عن نقص تقدير الذات ولتعويض

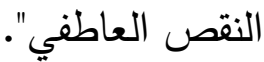


بمدينة مكة المكرمة، خلا ل العام الدراسي

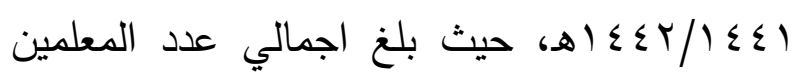

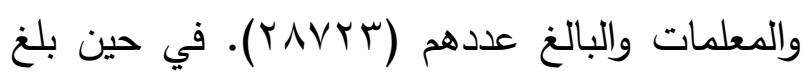

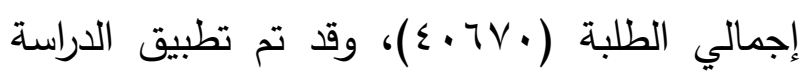

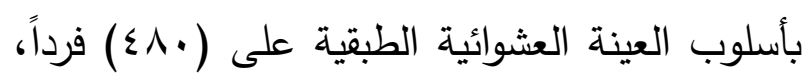
ويوضح الجدول التالي خصائص العينة:

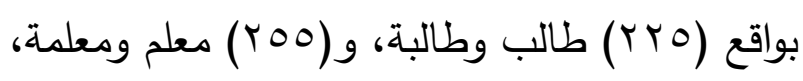

منهج الدراسة اتبعت الدراسة المنهج الوصفي التتبؤي (الارتباطي/ الفارقي)، والذي يقوم على مدى إمكانية التتبؤ

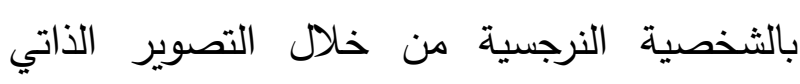
"السيلفي" وتحديد نوع هذه العلاقة ودرجتها بين متغيري التصوير الذاتي "السيلفي" والشخصية النرجسية لدى هلى لدئ معلمي ومعلمات وطلاب وطالبات المرحلة الثانوية.

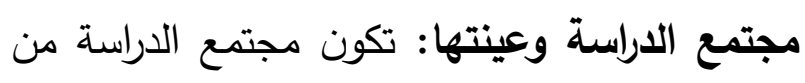
معلمي ومعلمات التعليم العام، وطلبة المدارس الثانوية جدول (1) خصائص عينة الاراسة من حيث الفئة (العمل) والنوع والعمر وعدد مرات نثر الصور وتعديلها

\begin{tabular}{|c|c|c|c|c|c|c|c|c|c|c|c|c|c|c|}
\hline \multicolumn{3}{|c|}{ تعليلي الصور } & \multicolumn{3}{|c|}{ نشر الصور يومياً } & \multicolumn{5}{|c|}{ العمر } & \multicolumn{2}{|c|}{ النوع } & \multirow{2}{*}{\multicolumn{2}{|c|}{ الفنية }} \\
\hline دائماً & أسمياناً & نادراً & كاكمز من & مرات & y & $\begin{array}{l}.8 \\
\text { فاكير }\end{array}$ & $\begin{array}{l}-\{\cdot \\
\leqslant 9\end{array}$ & $\begin{array}{c}-r . \\
r q\end{array}$ & $\begin{array}{c}-r \\
r\end{array}$ & من أثل & أنتى & ذكر & & \\
\hline$T \lambda$ & $q$ q & itr & iv & is & 19. & iv & iti & n & $y$ & - & in & $1+i$ & reo & \\
\hline$\% 1 \varepsilon, 9$ & $1 / r 4,9$ & $\gamma(2, \lambda T$ & $\%$ \%, & $\% A_{2} A$ & 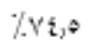 & $\%(\lambda, 2$ & $\%: \bullet 1,\{$ & $\% \pi v, A$ & $\%, \tau, \mathfrak{q}$ & - & $\% \varepsilon \gamma_{j}$, & $\% \bullet r, 0$ & $\% / r v_{1}, \tau$ & 年 \\
\hline 79 & 11. & $\because 4$ & iv & AT & 114 & - & - & $r$ & to & $M$ & iro & 1.. & reo & \\
\hline$\gamma / r \cdot \gamma$ & $\% \varepsilon \lambda, q$ & 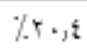 & $\%$ & $\% \pi 4, \varepsilon$ & $\%(1,4$ & - & - & $\%$ & $\% 10, \%$ & 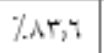 & $\% \varepsilon r, r$ & $\%(r, 3$ & $\% 4 r, \varepsilon$ & \\
\hline $1 . \gamma$ & T. & 149 & Ł & $1 T$. & $r \cdot \zeta$ & iv & iri & VT & \&) & $M$ & $r \varepsilon$ & 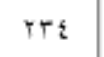 & $\{\lambda$. & الإبمالي \\
\hline
\end{tabular}

استخدمت الدراسة مقياس التصوير الذاتي الذي أدوات الدراسة:

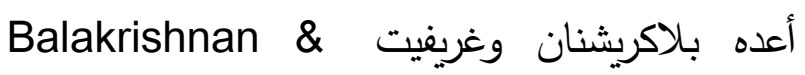

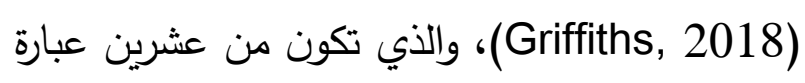

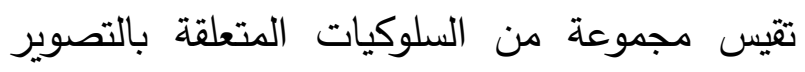

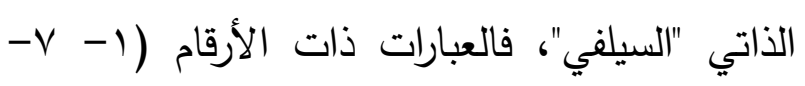
rا - 9 (1) توضح مدى تعلق الصور الذاتية بتعزيز

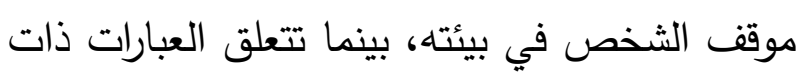

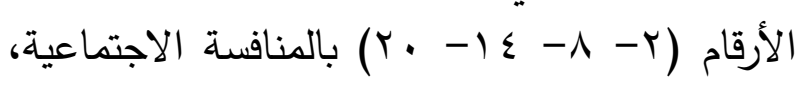

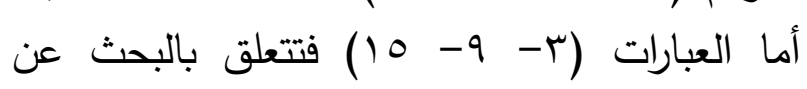

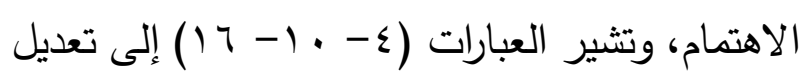

هدفت الدراسة إلى التعرف على التتبؤ بالتصوير

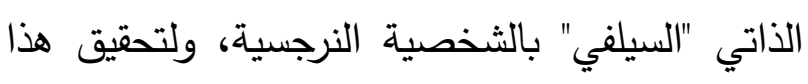
الهدف، وبعد الاطلاع على الدراسات السابقة المتعلقة بموضوع البحث تم استخدام مقاييس تم تعريبها من قبل

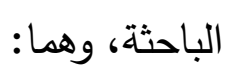
أولاً: مقياس التصوير الذاتي (السيلفي): من إعداد Balakrishnan \& Griffiths 
طالب من طلبة الجامعات الهندية، فقد أمكن من خلال

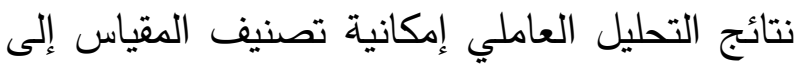
ستة عوامل، هي: (تعزيز موقف الثخص في بيئته، الثئه المنافسة الاجتماعية، البحث عن الاهتمام، تعديل الحالة المزاجية، الثقة بالنفس، المطابقة الذاتية). حيث الإني

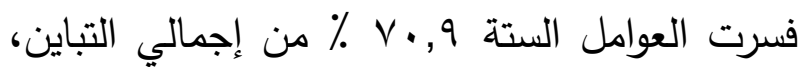

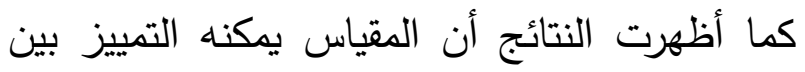

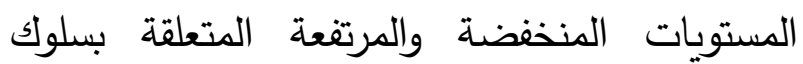

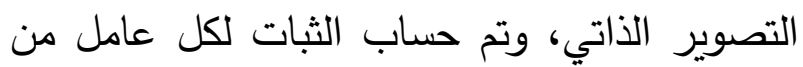

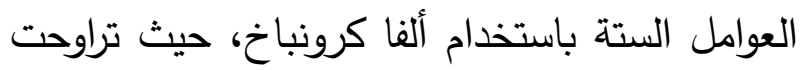

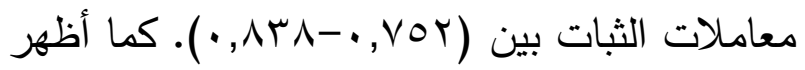

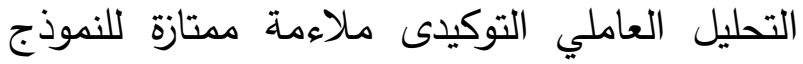
المكون من ستة عوامل، وتم تحميل جميع العناصر

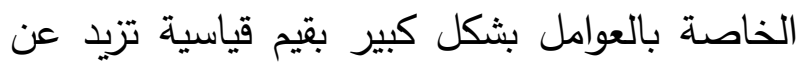

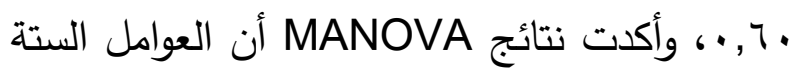
اختلفت بشكل كبير عبر مستوى درجه أو شده سلوك

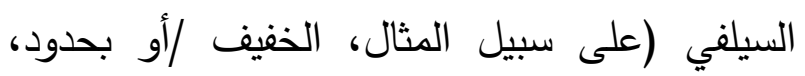
- وفي الدراسة الحالية تم التأكد من الصدق والثبات بالتطبيق على عينة استطلاعية مكونة من (·) (7)

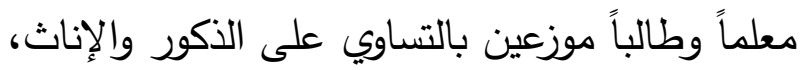
وفيما يلي توضيح نتائج صدق الاتساق الداخلي:

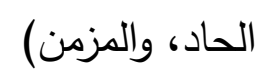

الحالة المزاجية، وتتعلق العبارات (0- IV V IV)

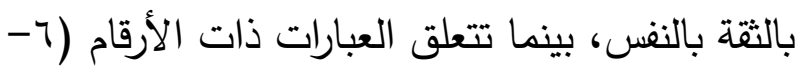

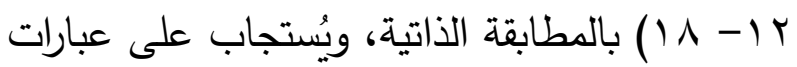

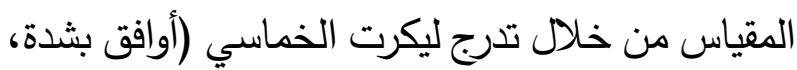

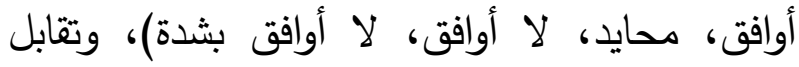

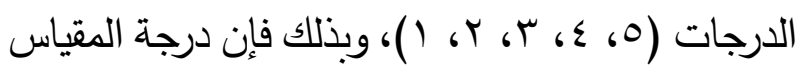

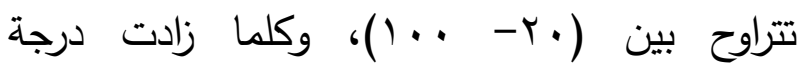
المستجيب زادت احتمالية اصابته باضطراب التصوير

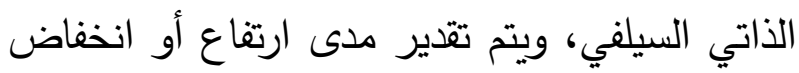
الدرجة على المقياس من خلال المتوسطات الحسابية،

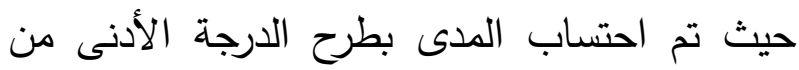

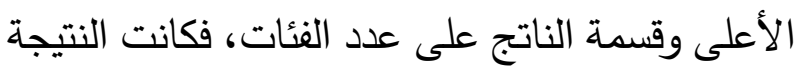

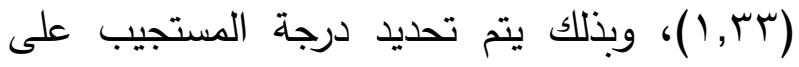

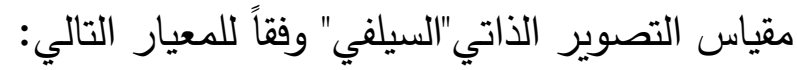
- درجة عالية: إذا تراوح المتوسط الحسابي بين $(0, \cdots-r, T V)$ - درجة متوسطة: إذا تراوح المتوسط الحسابي بين

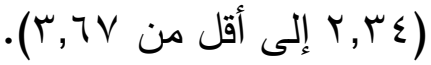

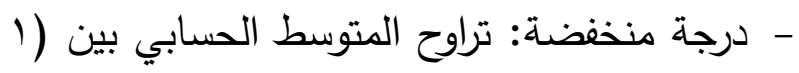
إلى أقل من ع ب, r. - وقد قام معدا المقياس بالتأكد من صدقه وثباته

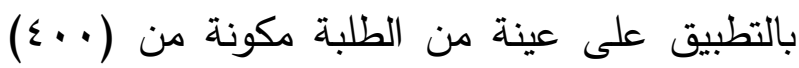
جدول (r) صدق الاتساق الاخلي لمقياس التصوير الأتي"السيلفي" (ن= • ؟)

\begin{tabular}{|c|c|c|c|c|c|c|c|}
\hline الارتباط & 5 & الارتباط & b & الارتباط & م & الارتباط & p \\
\hline$*, \vee \vee \vee q$ & 17 & $*, \wedge)$. & 11 & $*, \vee \vee 70$ & 7 & $*, \vee \vee \wedge \wedge$ & 1 \\
\hline$*, V \backslash r$ & IV & *, , مOr & ir & $*, \wedge \uparrow$. & v & $*, 79 \leq$ & r \\
\hline$* \cdot, T \leqslant \Lambda$ & 11 & $* ., 09 \mathrm{~V}$ & r & $*, \vee \vee Y q$ & $\wedge$ & $*, V \Gamma)$ & $r$ \\
\hline$*, 0 \wedge 9$ & 19 & $* \bullet, \vee \wedge \vee$ & $1 \varepsilon$ & $*, \vee \vee \wedge O$ & 9 & $*, v \cdot r$ & ؛ \\
\hline$*,, \leqslant \wedge$. & $r$. & $*,, \vee \vee \uparrow$ & 10 & $*,, \vee \vee \wedge$ & 1. & $*, \wedge \leqslant \wedge$ & 0 \\
\hline
\end{tabular}




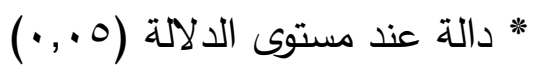

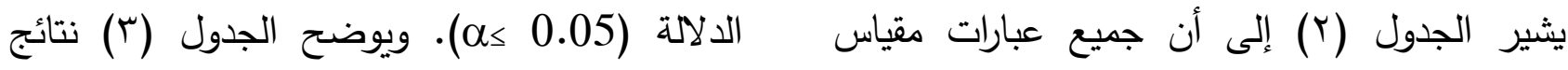
التصوير الذاتي"السيلفي" ذات ارتباطات دالة إحصائياً الثبات باستخدام طريقتي ألفا كرونباخ والتجزئة مع الدرجة الكلية للمقياس، حيث تراوحت قيم الارتباط النصفية:

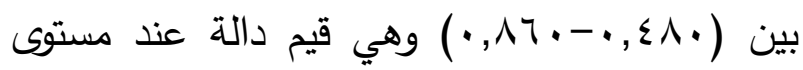

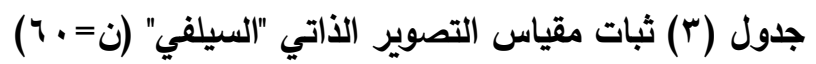

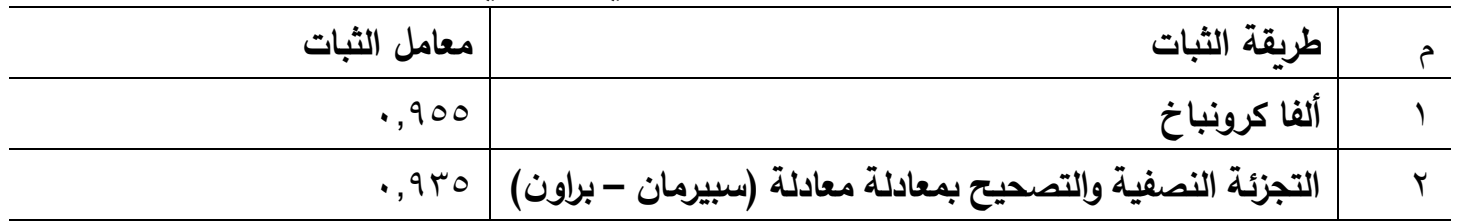

الأبعد (لا)، وبذلك تتراوح درجات المقياس بين

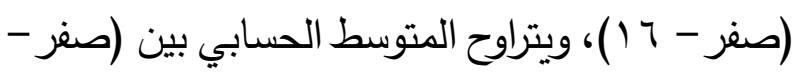

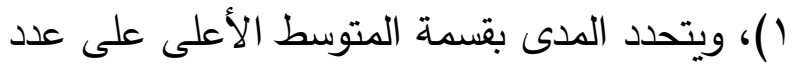

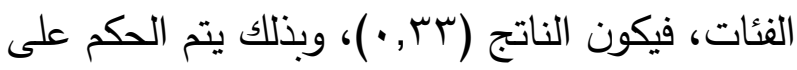
درجة النرجسية وفقاً للمعيار التالي: - النرجسية العالية: إذا كان تراوح مجموع الدرجات

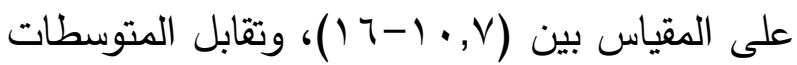

$$
\text { الحسابية بين (TV, TV •- ( ). }
$$

- النرجسية المتوسطة: إذا كان تراوح مجموع الدرجات على المقياس بين (ع,0-7, • (1) وتقابل المتوسطات الحسابية بين (ع r, •--77, • ). - النرجسية المنخفة: إذا كان مجموع الدرجات على المقياس أقل من (ع,0)، وتقابل المتوسطات الحسابية الأقل من (ع r, •). ويعتبر هذا المقياس مطور عن النسخة الاصلية الطويلة Raskin\& Terry عام 1988 ويهذف إنشاء
- يتضح من الجدول (r) أن مقياس التصوير الذاتي"السيلفي" يتمتع بمستويات ثبات مقبولة تراوحت بين (0 9 9 • ) بطريقة التجزئة النصفية بعد التصحيح

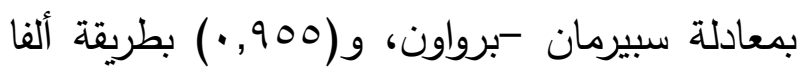
كرونباخ. ثانياً: مقياس النرجسية: المقياس الثخصية النرجسية Ames, Rose, Cameron $(Y \cdot\urcorner$. NPI-) استخدمت الدراسة مقياس الشخصية النرجسية 16 16 من إعداد أميس وروز وأندرسون ( Ames, Rose \& Anderson,2006)، وهو مقياس يتكون من (7 (1) زوج من العبارات، في كل زوج عبارة تدل

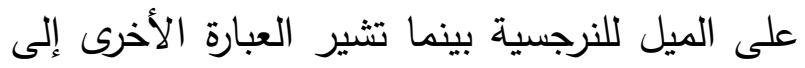

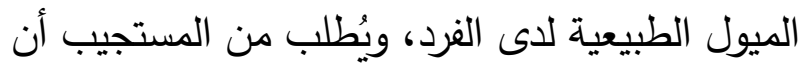
يختار من كل زوج العبارة التي تصف مشاعره ومعتقداته عن نفسه ويضع أمامها (نعم)، والعبارة 
مقياس قصير للنرجسية كوحدة واحدة، وإن كانت تمثل بقوة بمقياس NPI المكون من ع فقرة ، و كما الجوانب المختلفة للنرجسية والتي تم اكتثافها في أظهرت نتائج الصدق التقاربي ارتباط النرجسية إيجابيا مقياس40 الأصلي وقام مطورو المقياس بالانفتاح والانبساطوتقدير الذات والمراقبة الذاتية، كما بتطبيقه على عينة مكونة من (VVT) طالباً وطالبة أظهر الثبات بطريقة إعادة التطبيق بعد خمسة أسابيع من طلبة الجامعات بغرض التأكد من صدقه وثباته، أن معاملات الارتباط بين التطبيقين وصلت

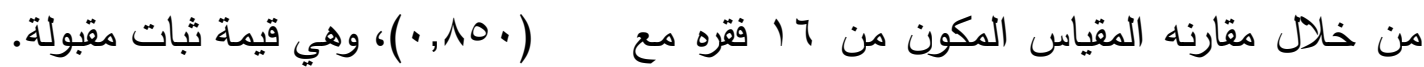

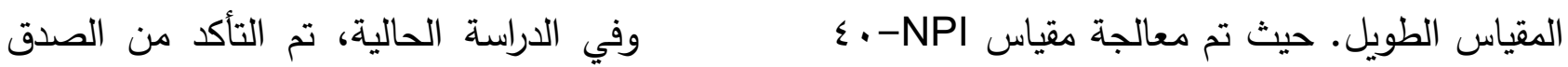
على عينة كبيرة من طلاب الجامعة وطبقت خمسة والثبات بالتطبيق على العينة الاستطلاعية المكونة من

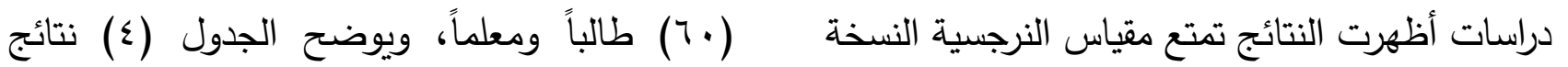
القصيرة بصدق وثبات قوي فقد بلغت العلاقة الاتساق الداخلي للأزواج الستة عشر المتضدنة في

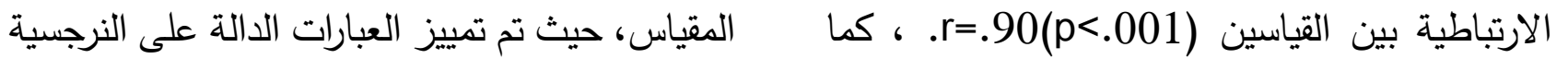

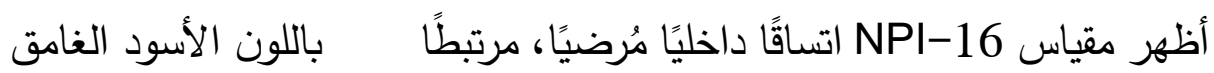

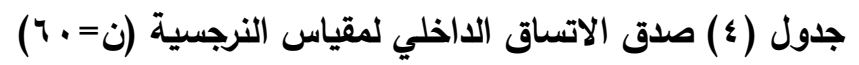

\begin{tabular}{|c|c|c|c|c|c|c|c|}
\hline الارتباط & ? & الارتباط & 5 & الارتباط & s & الارتباط & s \\
\hline$*, r q 9$ & \multirow{2}{*}{ IT } & *,०१९ & \multirow{2}{*}{9} & $* ., 01$. & \multirow{2}{*}{ 。 } & *.,०१ & \multirow{2}{*}{1} \\
\hline$*, 0 \wedge \wedge q$ & & $*, \Gamma \leq \varepsilon$ & & 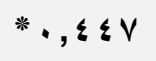 & & $*, r \xi 1$ & \\
\hline * & \multirow{2}{*}{$1 \varepsilon$} & O & \multirow{2}{*}{1.} & ד , , , & \multirow{2}{*}{7} & $*, r \leqslant r$ & \multirow{2}{*}{ r } \\
\hline$*$, r & & *.,017 & & $*, T_{0}$ & & דוז, . " & \\
\hline$*, \Gamma \backslash V$ & \multirow{2}{*}{10} & \& & \multirow{2}{*}{11} & $*, \leqslant 79$ & \multirow{2}{*}{$v$} & $*, r \leqslant \xi r$ & \multirow{2}{*}{ r } \\
\hline$*, r \diamond V$ & & $* \cdot, r \leq \varepsilon$ & & $*,, \diamond \vee r$ & & $\because \ldots, r Y$ & \\
\hline צזד, •*" & \multirow{2}{*}{17} & r & \multirow{2}{*}{ Ir } & $*, r \vee \wedge$ & \multirow{2}{*}{$\wedge$} & $*, \leqslant \vee V$ & \multirow{2}{*}{$\varepsilon$} \\
\hline$*, r Y q$ & & $*$, , $\leqslant$ ० V & & * & & $*^{*}, r \vee \wedge$ & \\
\hline
\end{tabular}

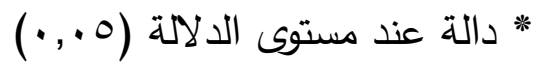

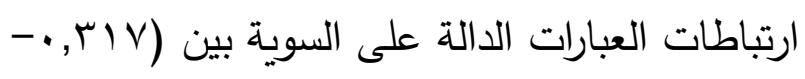
•

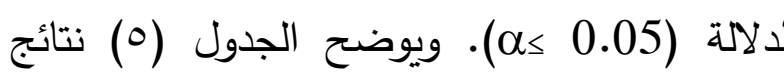
يتضح من الجدول (§) أن جميع عبارات المقياس ذات ارتباطات مع الدرجة الكلية للمقياس، فقد

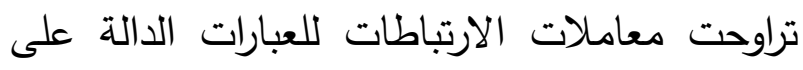

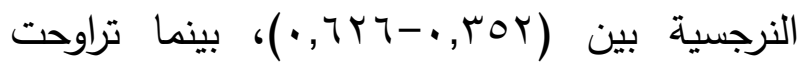


الثبات باستخدام طريقتي ألفا كرونباخ والتجزئة

\begin{tabular}{|c|c|c|}
\hline \multicolumn{2}{|c|}{ جدول (0) ثبات مقياس النرجسية (ن=• ؟) } & - \\
\hline معامل الثبات & يقة الثبات & ? \\
\hline$\cdot, \wedge \wedge \vee$ & ادلة كرونباخ ألفا & 1 \\
\hline$\cdot, \wedge 90$ & جزئة النصفية والتصحيح بمعادلة معادلة (سبيرمان - براون) & r \\
\hline
\end{tabular}

نص السؤال الأول على: ما مستوى انتشار التقاط الصور الذاتية "السيلفي" لدى معلمي وطلبة المرحلة الثانوية بمدينة مكة المكرمة؟ للإجابة عن هذا السؤال تم حساب المتوسطات الحسابية والانحرافات المعيارية لمقياس التصوير الذاتي "السيلفي" لكل فئة وللفئتين معاً، وفيما يلي توضيح النتائج:
تثير نتائج الجدول (0) إلى أن مقياس النرجسية يتمتع بمستويات ثبات مقبولة تراوحت بين (190 , · ) بطريقة

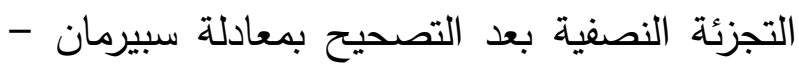

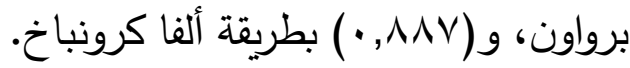
عرض ومناقشة النتائج عرض ومناقثة نتائج السؤال الأول

جدول (†) مستوى انتشار التصوير الذاتي"السيلفي" لاى معلمي وطلبة المرحلة الثانوية بمدينة مكة المكرمة

\begin{tabular}{|c|c|c|c|c|c|c|c|c|c|c|}
\hline \multicolumn{3}{|c|}{ العينة ككل } & \multicolumn{3}{|r|}{ الطلبة } & \multicolumn{3}{|r|}{ المعلمون } & \multirow{2}{*}{ الأبعاد } & \multirow{2}{*}{ p } \\
\hline المستوى & الانحراف & المتوسط & المستوى & الانحراف & المتوسط & المستوى & الانحراف & المتوسط & & \\
\hline متوسط & $\cdot, \wedge \leq 7$ & $r, \cdot r$ & متوسط & $\cdot$, YOA & $r, 1 \varepsilon$ & متوسط & $\cdot, q \cdot v$ & T,QY & تعزيز البيئة & 1 \\
\hline منخفض & •, ג & $r, r r$ & منخفض & - Vor & $r, r q$ & منخفض & $\cdot, 9 \cdot 7$ & $r, 19$ & الاجتماعية & r \\
\hline متوسط & •, $99 \leq$ & $r, r q$ & متوسط & $\cdot, 9 \vee 0$ & $r, 07$ & منخفض & $\cdot,(\vee 9)$ & $Y, Y \varepsilon$ & الاهتمام عن & $r$ \\
\hline منخفض & , $9 \times 1$ & $r, \mu r$ & متوسط & •, QYT & $r, r q$ & منخفض & $\cdot, 911$ & $r, Y V$ & تعديل الحالة & $\varepsilon$ \\
\hline متوسط & שד, & $r, 09$ & متوسط & $\cdot, 94 \wedge$ & $r, A r$ & متوسط & •, QYY & $r, r q$ & الثقة بالنفس & 0 \\
\hline منخفض & $\cdot, \wedge \vee q$ & $r, I r$ & منخفض & $\cdot, \lambda \vee T$ & $T, Y T$ & منخفض & $\cdot, \wedge \vee ५$ & $r, \cdot r$ & الذاتية & 1 \\
\hline متوسط & $\cdot, \vee \vee$. & $r, \varepsilon V$ & متوسط & $\cdot, Y \cdot r$ & $r, 09$ & متوسط & $\cdot, \wedge \Sigma \wedge$ & ז ד & توى الكلي & \\
\hline
\end{tabular}


الطلاب من الذكور والإناث لديهم أسباب مختلفة لالتقاط صور ذاتية وغالبًا ما يكون ذلك بمثابة عمل

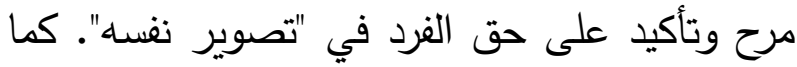
تتميز صور السيلفي بدورة حياتية تتتهي بعد تلقي التعليقات على منصة التواصل الاجتماعي، وهو ما

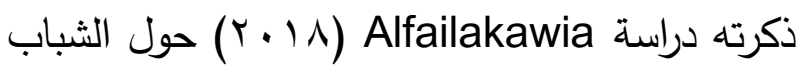
الكويتي عند أخذ صور السيلفي، خاصة الإناث، لا لانه يشعرون بالرضا عن أنفسهم وكيف يبدون. فهم قلقون للغاية بشأن صورتهم الذاتية على الإنترنت. فهؤلاء الثباب الكويتيون، وخاصة الإناث، في خطر لأن تقديرهم لذاتهم مرتبط بـ "التعليقات" و "الإعجابات" التي يتلقونها عند نشر صور السيلفي. عرض ومناقشة نتائج السؤال الثاني نص السؤال الثاني على: ما مستوى النرجسية لاى معلمي وطلبة المرحلة الثانوية بمدينة مكة المكرمة؟ للإجابة عن هذا السؤال تم حساب مجموع الاستجابات والمتوسطات الحسابية والانحرافات المعيارية لمقياس النرجسية لكل فئة وللفئتين معاً، وفيما يلي توضيح

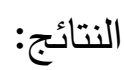

تشير نتائج الجدول (آ) على أن مستوى انتشار التصوير الذاتي "السيلفي" كان متوسطاً لدى معلمي

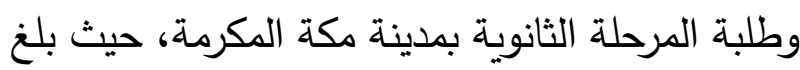
المتوسط الحسابي الكلي (Y, Y )، وبلغت المتوسطات الحسابية للمعلمين والطلبة على التوالي ( جr,ץ(Y,09)، وأما على مستوى أبعاد المقياس، فقد ظهرت ثلاثة أبعاد بمستوى متوسط، وهي: المنافئا الاجتماعية، البحث عن الاهتمام، الثقة بالنفس،

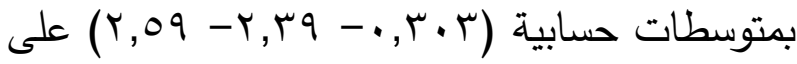
التوالي، بينما ظهرت ثلاثة أبعاد بدرجة منخفضة، وهي: المنافسة الاجتماعية، تعديل الحالة المزاجية،

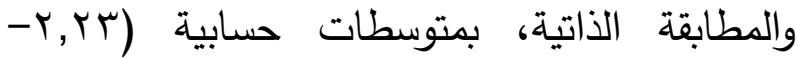

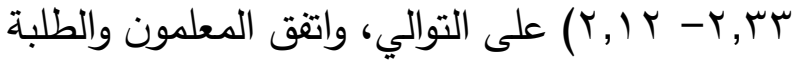
في مستوى أربعة أبعاد، بينما اختلفوا في بُعدي: البحث والاهتمام وتعديل الحالة المزاجية، حيث ظهرا بدرجة متوسطة لاى الطلبة ومنخفضة لاى المعلمين.

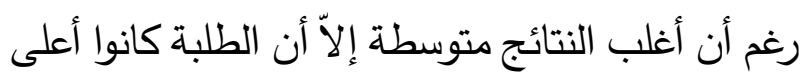
من المعلمين في بعض أبعاد التصوير الذاتي "السيلفي". لعل هذه النتيجة تأكيد لنتائج دراسة Shaha \& Tewarib 
جدول (V) مستوى النرجسية لاى معلمي وطلبة المرحلة الثانوية بمدينة مكة المكرمة

\begin{tabular}{|c|c|c|c|c|c|c|}
\hline المستوى & الرتبة & الانحراف & الحستوسط & متوسط الدرجات & الفئة & 5 \\
\hline متوسط & r & $\cdot, Y Y V$ & $\cdot, \leqslant 79$ & $v, \varepsilon q$ & معلمون & 1 \\
\hline متوسط & 1 &., 190 & $\cdot, 0.9$ & $\Lambda, 10$ & طلبة & r \\
\hline & متوسط & • & $\cdot, \Sigma \wedge \vee$ & $\vee, \wedge$. & \multicolumn{2}{|c|}{ المستوى الكلي للنرجسية } \\
\hline
\end{tabular}

تقدير الأداء قد تكون بسبب الرغبة في تعزيز مفهوم

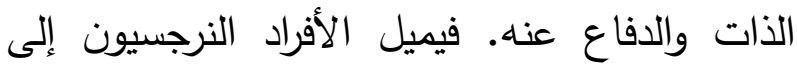
امتلاك توقعات غير واقعية لمستبقلهم أيضًا. ولاحظت Westerman, Bergman, Bergman \& دراسة Daly نرجسية، وجد أن هؤلاء الأفراد كانوا أكثر عرضة لتضخيم التوقعات حول حياتهم المهنية ورواتبهم وترقياتهم بعد التخرج، وظائف مستقبلية، فالطلية يمتلكون عملية تفكير غير واقعية حول أدائهم الأكاديمي ومساراتهم المهنية المستقبلية. وهذا بعكس المعلمين من الجنسين حيث يمتلكون تفكير واقعي تعود لنضجهم وكذلك تحقيق أهدافهم المستقبلية من

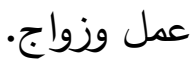

يتبين من نتائج الجدول (V) أن مستوى النرجسية كان متوسطاً لاى كل من معلمي وطلبة المرحلة الثانوية بمدينة مكة المكرمة، حيث بلغ المتوسط الحسابي الكلي (•^,^)، بينما بلغت المتوسطات الحسابية

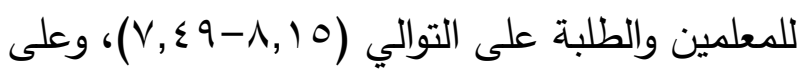
الرغم من أن جميعها قيم متوسطة إلاّ أن متوسطات النرجسية لدى الطلبة كانت أعلى من المعلمين. وتتفق هذه النتيجة مع دراسة Sukhdeep et al عام ملئه (2018) والتي أكدت على اعتدال مستوى النرجسية

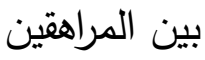
ولعل هذا تأكيد لما اقترحه كينيدي ولوتون وبلوملي Kennedy,Lauton \& Plumlee هناك آلية دفاعية تسمى "النزعة الدفاعية الأنانية" تلعب دورًا في الثقة الدفرطة في الأداء ، فالمبالغة في جدول (^) معامل الارتباط بين مستوى النرجسية والتصوير الذاتي "السيلفي" بأبعاده لاى المعلمين والطلبة

\begin{tabular}{|c|c|c|c|c|c|c|}
\hline \multicolumn{3}{|r|}{ النرجسية } & & & \multirow{2}{*}{ المتغيرات } & \multirow{2}{*}{ الفئة المة } \\
\hline & الدلالة - مالة & معامل الارتباط & & & & \\
\hline 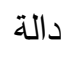 & $\cdot, .10$ & $* *$, , YOY & تعزيز البيئة & \multirow{4}{*}{ الذاتي } & \multirow{4}{*}{ "النيلفي" } & \multirow{4}{*}{ المعلمون } \\
\hline 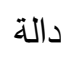 & $\cdot, \ldots$ & $* * *, r Y q$ & المنافسة الاجتماعية & & & \\
\hline 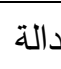 & $\cdot, \ldots$ & ***,r|r & البحث عن الاهتمام & & & \\
\hline 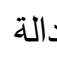 & $\cdot, ., r$ & $* *,, \backslash \Lambda \varepsilon$ & تعديل الحالة المزاجية & & & \\
\hline
\end{tabular}




\begin{tabular}{|c|c|c|c|c|c|c|}
\hline دالة & $\cdot, \cdots 1$ & $* *, r \mid r$ & الثقة بالنفس & & & \\
\hline دالة & $\cdot, \cdots r$ & $* *, 19$. & المطابقة الذاتية & & & \\
\hline دالة & $\cdot, \cdots$ & $* *, Y Y I$ & الارتباط الكلي & & & \\
\hline دالة & $\cdot, \cdots$ & $* *, Y \bigcirc \wedge$ & تعزيز البيئة & \multirow{7}{*}{ الذاتي } & \multirow{7}{*}{ "التصيلفي" } & \multirow{7}{*}{ الطلبة } \\
\hline دالة & $\cdot, \cdots$ & $* *, \Gamma 01$ & المنافسة الاجتماعية & & & \\
\hline دالة & $\cdot, \cdots$ & $* *, r \vee r$ & البحث عن الاهتمام & & & \\
\hline دالة & $\cdot, \cdots T$ & $* *, r Y r_{0}$ & تعديل الحالة المزاجية & & & \\
\hline دالة & $\cdot, \cdots$ & $* *$, ro. & الثقة بالنفس & & & \\
\hline دالة & $\cdot, \cdots$ & $* *, r \circ V$ & المطابقة الذاتية & & & \\
\hline دالة & $\cdot, \cdots$ & $* *, \Gamma)$ & الارتباط الكلي & & & \\
\hline دالة & $\cdot, \cdots$ & $* *, r \cdot r$ & تعزيز البيئة & \multirow{7}{*}{ الذاتي } & \multirow{7}{*}{ "التصيلفي" } & \multirow{7}{*}{ ككل } \\
\hline دالة & $\cdot, \cdots$ & $* *, r \wedge$. & المنافسة الاجتماعية & & & \\
\hline دالة & $\cdot, \cdots$ & $* *, r \leqslant \wedge$ & البحث عن الاهتمام & & & \\
\hline دالة & $\cdot, \cdots$ & $* *, r>0$ & تعديل الحالة المزاجية & & & \\
\hline دالة & $\cdot, \cdots$ & $* *, r \leqslant r$ & الثقة بالنفس & & & \\
\hline دالة & $\cdot, \cdots$ & **, Y Y Y & المطابقة الذاتية & & & \\
\hline دالة & $\cdot, \cdots$ & $* *, Y>0$ & الارتباط الكلي & & & \\
\hline
\end{tabular}

النرجسية، كما يؤدي زيادة مستوى النرجسية إلى زيادة مستوى التقاط الصور الذاتية في جميع الأبعاد والدرجة الكلية لدى المعلمين والطلبة. وتتفق هذه النتيجة مع أغلب نتائج الدراسات التي تناولت العلاقة بين النرجسية والتصوير الذاتي "السيلفي" كدراسة كلا 2020; Anjum \& Kazmi,2019; Dom \& Venkatachalam, 2019;Biolcati \&Passini,2018; Sukhdeep et al,2018 ,

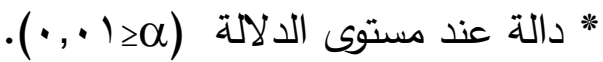
يتبين من الجدول رقم (^) وجود علاقة ارتباطية موجبة ودالة إحصائياً بين مستوى النرجسية والتصوير الذاتي بأبعاده الستة لاى كل من المعلمين والطلبة على حده ولديهم مجتمعين؛ حيث بلغت القيمة الكلية لمعامل الارتباط (07, •)، بينما بلغت قيمة الارتباط لدى

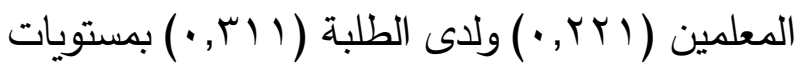
دلالة ( . . ....)، وهي قيم دالة إحصائياً عند مستوى الدلالة (0.01 0.01 )، وتثير إلى أنه كلما زاد مستوى التصوير الذاتي "السيلفي" او أحد أبعاده زاد مستوى 
2018; Dutta et al, 2018; Hernowo \& Mashoedi,2018;

- McCain et al, 2015 ; Barry et al,2015;

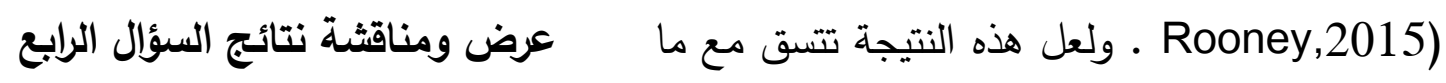

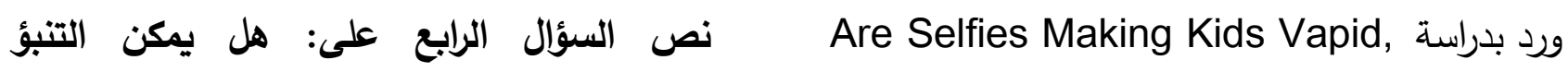
Narcissistic and Lazy

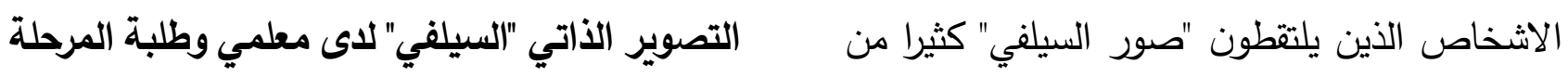

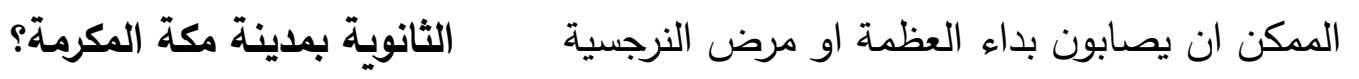

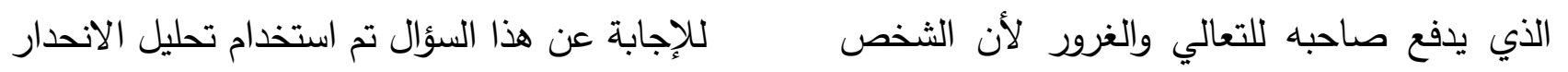

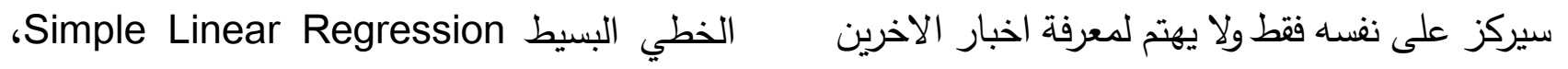

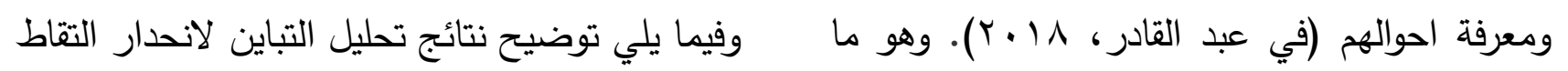

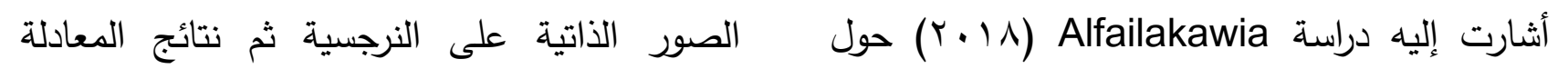
الشباب الكويتي في أخذ صور السيلفي، أن الأشخاص التتبؤية:

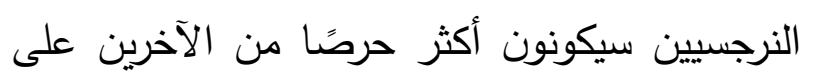
التصوير الذاتي خاصة، وتحرير تلك الصور ، ونشر الأنر

جدول (9) ملخص نموذج الاندار الخطي البسيط

\begin{tabular}{|c|c|c|c|c|c|}
\hline $\begin{array}{r}\text { الخطأ المعياري للتقدير } \\
\text { Std. Error of the } \\
\text { Estimate }\end{array}$ & معامل التحديد التوافقي & $\begin{array}{r}\text { معامل } \quad \text { التحديد } \\
\text { R2 }\end{array}$ & معامل الارتباط R & الفئة & النموذج \\
\hline • & $\cdot, \cdot \leq 0$ & $\cdot, \cdot \leq 9$ & • & المعلمون & 1 \\
\hline$\cdot, 1 \wedge 7$ &., .94 &., .97 & ון, & الطلبة & \\
\hline
\end{tabular}

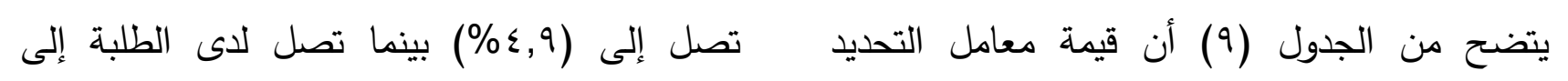

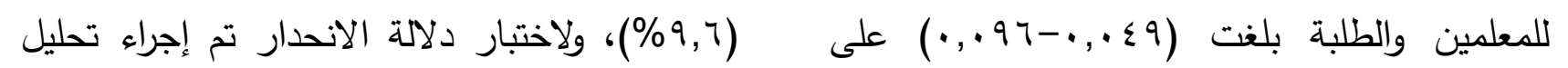

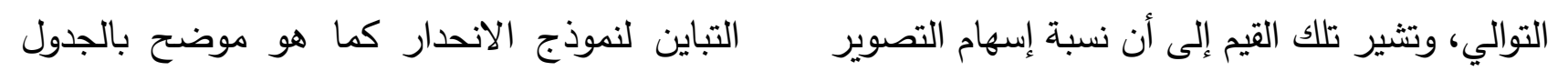
الذاتي "السيلفي" في الثخصية النرجسية لاى المعلمين التالي: 
جدول ( • 1) تحليل التباين لانحار التصوير الذاتي "السيلفي" على النرجية لاى الطلبة والمعلمين

\begin{tabular}{|c|c|c|c|c|c|c|c|}
\hline & & & & مجموع المربعات & & & \\
\hline Sig. مسلوى Sig & قيمة "ف" F & مeوسط المربعات & الحرية df & $\begin{array}{l}\text { Sum of } \\
\text { squares }\end{array}$ & مصدر التباين & الفئة & المتغير \\
\hline \multirow{3}{*}{ دالة } & \multirow{3}{*}{$1 r, 900$} & $17 \pi, v 00$ & 1 & $17 r, v 00$ & Regression & \multirow{3}{*}{ المعلمون } & \multirow{6}{*}{ التاط التاطية } \\
\hline & & $M, \leqslant 7$. & ror & r।9४,99६ & البواقي & & \\
\hline & & & ros & 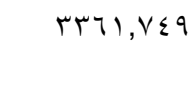 & $\begin{array}{c}\text { المجموع } \\
\text { Total }\end{array}$ & & \\
\hline \multirow{3}{*}{ دالة } & \multirow{3}{*}{$r r, V T \leq$} & $r \cdot, \lambda \leqslant r$ & 1 & $r) \cdot, \Lambda \leqslant r$ & Regression & \multirow{3}{*}{ الطلبة } & \\
\hline & & $\wedge, \wedge \uparrow)$ & Tr & $19 \vee 7, \cdot r$. & البواقي $\begin{array}{r}\text { Residual } \\
\text { Reside }\end{array}$ & & \\
\hline & & & TYE & Y)ム & $\begin{array}{r}\text { المجموع } \\
\text { Total }\end{array}$ & & \\
\hline
\end{tabular}

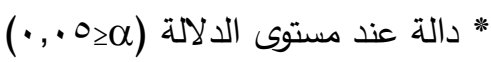

يشير إلى أن التصوير الذاتي "السيلفي" يؤثر على مستوى النرجسية لدى الطلبة والمعلمين. وللوصول للمعادلة التنبؤية؛ فقد تم تحديد درجة اسهام التصوير الذاتي "السيلفي" في التنبؤ بالنرجسية، والجدول التالي

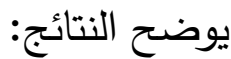

يتضح من الجدول ( • () أن قيمة (F) لاختبار الدلالة الإحصائية للتنبؤ بمستوى النرجسية من خلال مستوى التصوير الذاتي "السيلفي" بلغت (1,900) للمعلمين، بينما بلغت ( (Y,VT) للطلبة، وهي قيم دالة إحصائياً عند مستوى الدلالة (0.,.•)، وهو ما جدول رقم (1 1 ) نتائج المعادلة التنبؤية بالنرجسية من خلال مستوى التصوير الذاتي "السيلفي" لاى المعلمين والطلبة

\begin{tabular}{|c|c|c|c|c|c|c|}
\hline مستوى الدلالة & "T" قيمة "T & $\begin{array}{r}\text { Beta قيمة بيتا } \\
\text { Standardized } \\
\text { Coefficients }\end{array}$ & $\begin{array}{r}\text { الخطأ المعياري } \\
\text { Std-Error }\end{array}$ & $\begin{array}{r}\text { B قيمة } \\
\text { Unstandardized } \\
\text { Coefficients }\end{array}$ & & الفئة \\
\hline • ., ••دالة & $\vee, q \vee 1$ & - &., 74. & $0, Y 71$ & الثابت & \multirow[b]{2}{*}{ المعلمون } \\
\hline 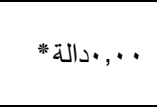 & $r, 099$ & $\cdot, Y Y I$ & זדז, & $\cdot, 9 \leqslant 9$ & "التصوير الذاتي & \\
\hline • . , •دالة" , & \rceil,$\cdot \Sigma$. & - & $\cdot, \mathrm{VON}$ & $\varepsilon, 011$ & الثابت & \multirow[b]{2}{*}{ الطلبة } \\
\hline • , , •دالة * & $\varepsilon, \wedge \vee \wedge$ & •, & سגז, & I,rul & "التصيلفير الذاتي & \\
\hline
\end{tabular}


* دالة عند مستوى الدلالة (ه • •, •)

"السيلفي" ومحاولات الحصول على الاهتمام والإعجاب من الآخرين يظهر جانبا من النرجسية والاستعراضية، كذلك اتفقت جزئيا مع دراسة Sorokowski et al سلوك نشر الصور الذاتية للمرأة لم يكن مرتبطًا بشكل عام بنتائج النرجسية، على النقيض من ذلك، فإن النتائج النرجسية الإجمالية للرجال تتبأت بشكل إيجابي بنشر صور شخصية وصور ذاتية مع شريك وصور Vazire et al شخصية جماعي وهو تأكيد لما ذكره

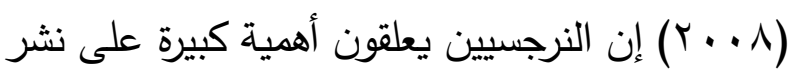
صور شخصية خاصة بهم، في مواجهة جمهور من المعجبين، وأهمية أقل للنشر بشكل عام أو مشاركة صور شخصية جماعية أو شريك. وتتسق هذه النتيجة والدراسات السابقة والاطر النظرية والتي ترى أن من خلا سلوك إدماني مرضي في التصوير الذاتي "السيلفي" والنشر المتكرر يمكن أن يكثف عن سلوك

$$
\text { نرجسي مضطرب. }
$$

عرض ومناقشة نتائج السؤال الخامس

نص السؤال الخامس على: هل توجد فروق ذات دلالة إحصائية بين متوسطات استجابات أفراد العينة على مقياسي التصوير الذاتي "السيلفي" والنرجسية تعزى لاختلاف: العمل، الجنس، العمر، عدد مرات نشر الصور، عدد مرات تعديل الصور؟ للإجابة عن هذا السؤال تم استخدام اختبار "ت" (T-test) للفروق وفقاً للعمل والجنس، واختبار تحليل التباين الأحادي
يتضح من الجدول (1) أنه يمكن التنبؤ بمستوى النرجسية لدى معلمي وطلبة المرحلة الثانوية بمدينة مكة المكرمة من خلال مستوى التصوير الذاتي "السيلفي" حيث بلغت قيم بيتا Beta المعيارية

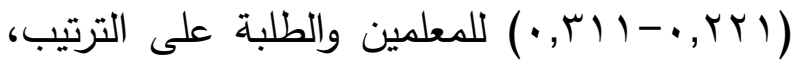
وهذا يعني أنه كلما زاد مستوى التصوير الذاتي "السيلفي" بمقدار وحدة كلما زاد مستوى النرجسية لدى المعلمين بمقدار ( ا Y, , ) وحدة، ولدى الطلبة بمقدار

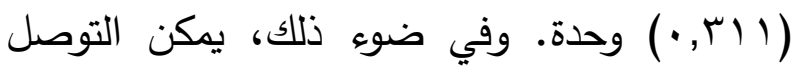
للمعادلتين التنبؤيتين التاليتين: المعادلة التتبؤية لمستوى النرجسية لدى المعلمين بدلالة التصوير الذاتي "السيلفي" = آج, "السيلفي" (1) المعادلة التنبؤية لمستوى النرجسية لدى الطلبة بدلالة التصوير الذاتي "السيلفي" =

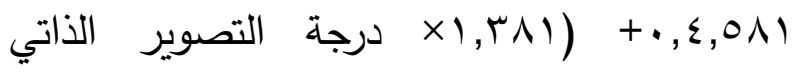
"السيلفي" (ال)

وهذا يتسق مع العديد من الدراسات التي أظهرت بإمكانيه التنبؤ بالسيلفي في النرجسية كدراسة Adler والتي كثفت عن النرجسية المنخفضة ت أبأت (Y) بنشر صور السيلفي، ودراسة \& Bunker \& Gwalani سيلفي للمشاركين، وهو ما أشارت اليه دراسة Weiser 
لاستخراج الثروق وفقاً لمتغيرات: العمر، (ANOVA) للمقارنات البعدية، وفيما يلي توضيح ومرات نشر الصور الذاتية يومياً، وتعديل الصور ل النتائج:

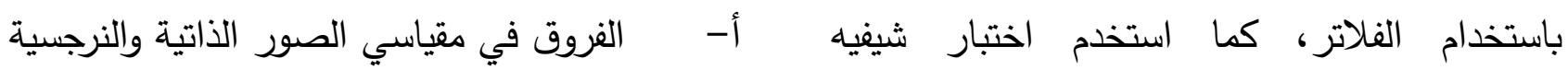
تبعاً لمتغير المهنه:

جدول (Y T) نتائج اختبار "ت" (T- Test) للفروق تبعاً لمتغير المهنه:

\begin{tabular}{|c|c|c|c|c|c|c|c|c|}
\hline مستوى الدلالة & قيمة(ت) & المتوسطين & الانحراف المعياري & الحستوسطي & العدد & المهنة & & المقياس \\
\hline $\mathscr{H}, \ldots r$ & \multirow{2}{*}{ r,Ir } & \multirow{2}{*}{, } & $\cdot, r \cdot r$ & $r, 09$ & rro & طالب & \multirow{2}{*}{ الأني } & \multirow{2}{*}{ "السيلفي" التصوير } \\
\hline دالة" & & & $\cdot, \lambda \leqslant \wedge$ & $r, r 4$ & roo & معلم & & \\
\hline$\cdot$, r. & \multirow{2}{*}{$r, 11$} & \multirow{2}{*}{$\cdot, \cdot \leq}$. &., 190 & $\cdot, 0.9$ & rro & طالب & & \multirow{2}{*}{ مقياس النرجسية } \\
\hline دالة" & & & . TYV & 促, & roo & معلم & & \\
\hline
\end{tabular}

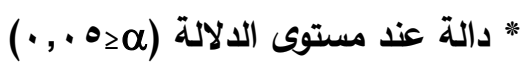

يتبين من الجدول (r ( ) وجود فروق دالة إحصائياً عند "السيلفي" وفي مستوى النرجسية من المعلمين. وهو ما

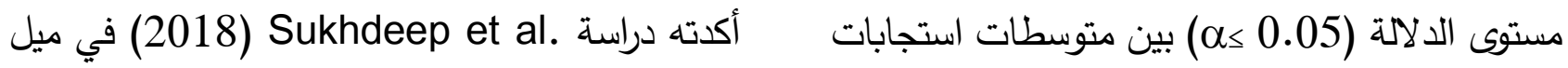
الطلبة والمعلمين على مقياسي التصوير الذاتي وتفضيل الطلبة للتصوير الذاتي "السيلفي"، وتحرير "السيلفي" والنرجسية، حيث كانت قيم "ت" دالة عند صور السيلفي قبل نشرها، وفصلها وتمييزها عن صور مستويات أقل من (0., •)، وبمقارنة المتوسطات السيلفي الجماعية حيث أصبحت حقيقة ملحوظة الحسابية يتضح أن الفروق لصالح الطلبة في للثقافة الجديدة لجيل الثباب. المقياسين، بمعنى أنهم أعلى في التصوير الذاتي لبن ب- الفروق في مقياسي التصوير الذاتي "السيلفي" والنرجسية تبعاً لمتغير الجنس:

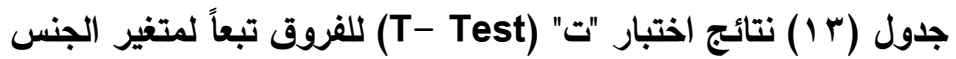

\begin{tabular}{|c|c|c|c|c|c|c|c|}
\hline مستوى الدلالة & قيمة(ت) & المتوسطين $\quad$ بين & الانحراف المعياري & الحستوسطي & العدد & الجنس & المقياس \\
\hline$\cdot, .71$ & \multirow{2}{*}{$r, i r$} & \multirow{2}{*}{ - } & -, $\vee$ १ & $r, \varepsilon$. & TrE & ذكر & \multirow{2}{*}{ "السيلفي" التصوير } \\
\hline غير دالة & & & - YAO & r,or & $r \leqslant T$ & أنثى & \\
\hline$\cdot, \cdot V \varepsilon$ & \multirow{2}{*}{$r, 11$} & \multirow{2}{*}{$\cdot, \cdot r \varepsilon$} & $\cdot, r>0$ & $\cdot, 0.0$ & TrE & ذكر & \multirow{2}{*}{ مقياس النرجسية } \\
\hline غير دالة & & & .rII & •, $\leqslant \vee$. & $T \leq T$ & أنثى & \\
\hline
\end{tabular}


الإناث، في خطر لأن احترامهم لذاتهم مرتبط بـ

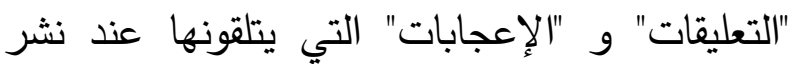
صور السيلفي، في حين اختلفت نتائج الدراسة الحالية

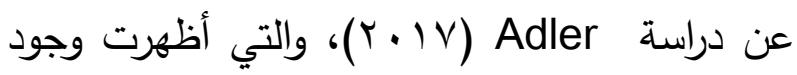
اختلاف بين الجنسين بالسيلفي لصالح الذكور، واختلفت الدراسة الحالية مع العديد من الدراسات حول لين لئل وجود اختلاف بين الذكور والاناث في سمه النرجسية لصالح الذكور كدراسة \&oursiera, Gioiaa Bunker \& عام Griffiths Sorokowski et al Gwalani

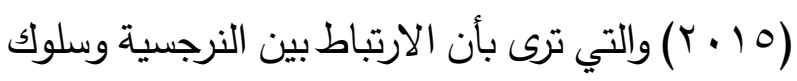
نشر الصور الشخصية ضعيف نسبيًا بين النساء

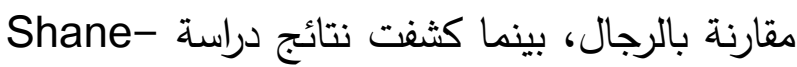
Simpson الولايات المتحدة لديهم نرجسية عالية ونشروا صور ذاتيه بشكل متكرر، ويمكن تقسير ذلك إلى إنه سلوك لعرض الذات تلعب ثقافة المجتمع وقيمة الدينية دور
تشير نتائج الجدول (r ا ) إلى أنه لا توجد فروق دالة إحصائياً بين متوسطات استجابات الأكور والإناث على مقياسي التصوير الذاتي "السيلفي" والنرجسية،

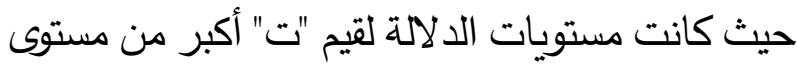
الدلالة (0.05 0.05$).$ دراسة (Y.19)Dom \& Venkatachalam

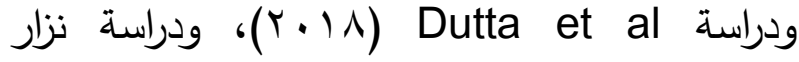
(Y) والتي كثفت عن عدم وجود فروق بين (r) الجنسين في التصوير الذاتي "السيلفي" في حين اختلفت الدراسة الحالية مع العديد من الدراسات حول وجود اختلاف بين الذكور والاناث في السيلفي لصالح Boursiera , Gioiaa \& Griffiths الاناث كدراسة ,2020; Anjum \& Kazmi,2019; Dhir et al , 2016 ; Sedgewick, Flath , \&Elias , 2017 والتي أظهرت أن الصور الثخصية شائعة

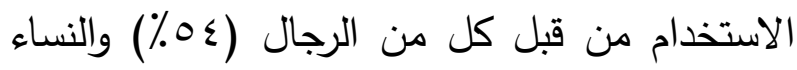

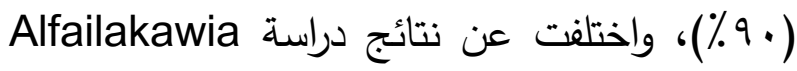

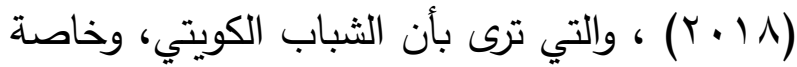

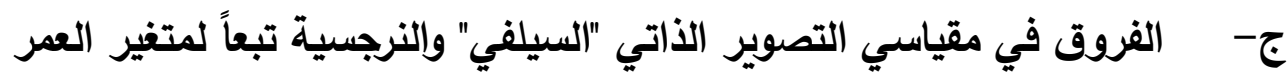


جدول ( ) ا ) المتوسطات والانحرافات المعيارية للفئات العمرية على مقياسي التصوير الأتي "السيلفي" والنرجسية

\begin{tabular}{|c|c|c|c|}
\hline الانحراف المعياري & المتوسط الحسابي & الفئة العمرية & المقياس \\
\hline., 017 & r,Tr & أقل من عشرين سنة & \multirow{5}{*}{ الذاتي "السيلفي" التصوير } \\
\hline$\cdot, \Gamma$. & r,Or & من · r إلى أقل من •r سنة & \\
\hline$\cdot, 10$. & $r, \varepsilon \varepsilon$ & من · r إلى أقل من · ع سنة & \\
\hline$\cdot, r 00$ & r, זᄉ & من · ؛ إلى أقل من •0 سنة & \\
\hline$\cdot, \perp \wedge V$ & $r, \cdot \varepsilon$ & من • م سنة فأكبر & \\
\hline$\cdot, r) \leqslant$ & $\cdot$, or. & أقل من عشرين سنة & \multirow{5}{*}{ مقياس النرجسية } \\
\hline$\cdot, r \cdot 1$ & $\cdot, \leq 77$ & من · r إلى أقل من •r سنة & \\
\hline • & $\cdot, 011$ & من · r إلى أقل من • ؛ سنة & \\
\hline ( & $\cdot, \leqslant 09$ & من · ؛ إلى أقل من •0 سنة & \\
\hline . & $\cdot, \varepsilon)$ & من ·0 سنة فأكبر & \\
\hline
\end{tabular}

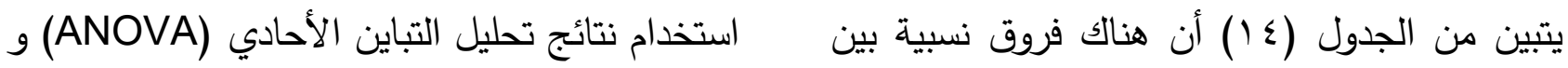

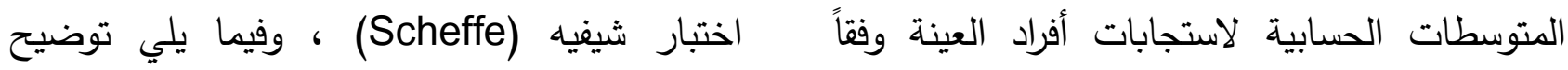
للفئات العمرية، وللتعرف على ما إذا كان لهذه الفروق النتائج: دلالة إحصائية واتجاه نحو إحدى الفئات، فقد تم جدول (ه 1) نتائج تحليل التباين الأحادي (ANOVA) للكثف عن الفروق تبعاً لمتغير العمر

\begin{tabular}{|c|c|c|c|c|c|c|c|}
\hline مستوى & قيمة (ف) & متوسط المربعات & درجة الحرية & المربعات & مصدر التباين & & المقياس \\
\hline \multirow{3}{*}{ دالة* } & \multirow{3}{*}{$0,1 \wedge 7$} & $r, \Sigma q \mu$ & $\varepsilon$ & $1 T, 9 V Y$ & بين المجموعات & \multirow[t]{3}{*}{ الذاتي } & \multirow{3}{*}{ "السيلفي" التصوير } \\
\hline & & \multirow[t]{2}{*}{ ( } & $\leqslant \vee 0$ & $r \wedge 0, r \cdot l$ & داخل المجموعات & & \\
\hline & & & $\sum \vee q$ & rq৭, rVr & الإجمالي & & \\
\hline \multirow{3}{*}{ دالة * , . • } & \multirow{3}{*}{$r, v r}$. & $\cdot, 17 V$ & $\varepsilon$ & צד & بين المجموعات & & \multirow{3}{*}{ مقياس النرجسية } \\
\hline & & $0 \leqslant 0$ & $\leqslant V_{0}$ & $r, r \cdot r$ & داخل المجموعات & & \\
\hline & &, 90 & $\leqslant \vee q$ & $r \mid, \wedge V \Psi$ & الإجمالي & & \\
\hline
\end{tabular}

يشير الجدول (10) إلى وجود فروق دالة إحصائياً شيفيه (Scheffe) للفروق البعدية، ويوضح الجدول

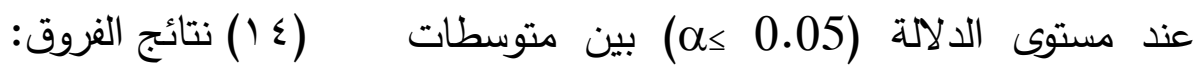
استجابات أفراد العينة على مقياسي التصوير الذاتي الذاني

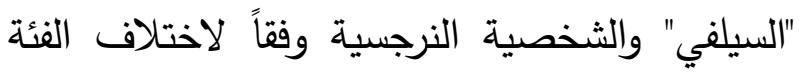
العمرية، ولمعرفة اتجاهات الفروق تم استخدام اختبار 
جدول (1 1 ) نتائج اختبار شيفيه (Scheffe) للفروق البعدية في مستويي التصوير الذاتي "السيلفي" والثخصية

\begin{tabular}{|c|c|c|c|c|c|c|c|}
\hline فأكبر & من من · • إلى أقل & 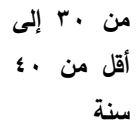 & 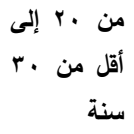 & سنة أقل من عشرين & الحسابي & الفئة العمرية & المقياس \\
\hline$*, 0 \vee \wedge$ & $\cdot, Y T V$ & $\cdot, 1 \vee 9$ & $\cdot, 1 \cdot r$ & - & r, & أقل من عشرين سنة & \multirow{5}{*}{ مقياس الذاتي "السيلفي" } \\
\hline$\cdot, \leqslant \circ \mathrm{V}$ & $\cdot, 1 \Gamma \varepsilon$ & $\cdot, \cdot \vee V 7$ & - & $\cdot, 1 \cdot r-$ & r,or & من · r إلى أقل من •r سنة & \\
\hline$\cdot, r 9 \wedge$ & $\cdot, .0 \mathrm{~V}$ & - & $\cdot, \cdot \vee \vee \neg-$ & $\cdot, 1 \vee 9-$ & $r, \Sigma \varepsilon$ & من ·r إلى أقل من •؛ سنة & \\
\hline$\cdot, \varepsilon \Gamma \cdot$ & - & $\cdot, .0 \mathrm{~V}-$ & $\cdot, 1 \Gamma \leq-$ & $\cdot, r T V-$ & $r, r \wedge$ & من · ؛ إلى أقل من •• سنة & \\
\hline- & $\cdot, \varepsilon \uparrow \cdot-$ & $\cdot$, r৭४- & $\cdot,\{\circ \mathrm{V}-$ & ${ }^{*} \cdot$, OVN- & $r, \cdot \varepsilon$ & من •• سنة فأكبر & \\
\hline$* \cdot, 1 \cdot 1$ & $\cdot, .09$ & $\cdot, \cdot, 1-$ & $\cdot, .0 r$ & - & $\cdot$, or. & أقل من عشرين سنة & \multirow{5}{*}{ مقياس النرجسية } \\
\hline$\cdot, .00$ & $\cdot, \cdots \vee$ & $\cdot, .0 \leqslant-$ & - & $\cdot, .0 Y-$ & $\cdot, \sum 74$ & من · r إلى أقل من •r سنة & \\
\hline$\cdot, 1 \cdot 9$ & $\cdot, \cdot 71$ & - & $\cdot, .0 \leqslant$ &,,$\cdots$ & $\cdot, 011$ & من ·r إلى أقل من •؛ سنة & \\
\hline$\cdot, \cdot \leq \wedge$ & - & $\cdot, \cdot 7 \cdot-$ & $\cdot, \cdot, \vee-$ & $\cdot, .09-$ & $\cdot, \leqslant 09$ & من ·ـ إلى أقل من •• سنة & \\
\hline- & $\cdot, \cdot \leq \wedge-$ & $\cdot, 1 \cdot 9-$ & $\cdot, .00-$ & $* \cdot 1 \cdot 1-$ & $\cdot, \varepsilon)$. & من ·• سنة فأكبر & \\
\hline
\end{tabular}

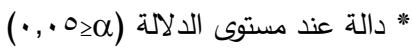

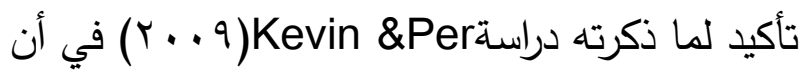
النرجسية في حد ذاتها موجودة كنمط بالثخصية

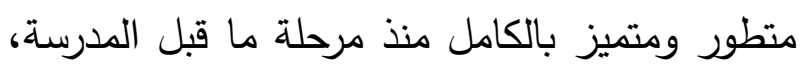

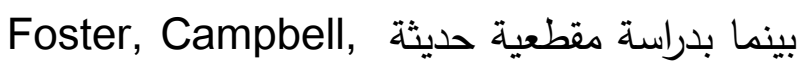
(2003) \& Twenge انخفضت مع تقدم العمر في العينات عبر الجنسيات التي تتراوح في العمر من ^ إلى بـ عامثا.

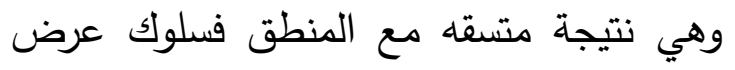

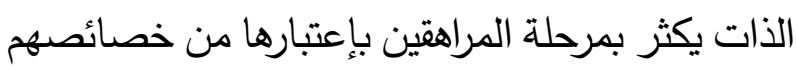
النفسية، كما تثير الإحصاءات إلى أن النرجسية

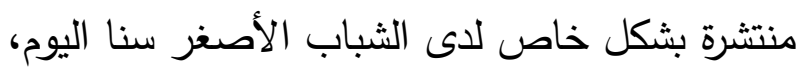

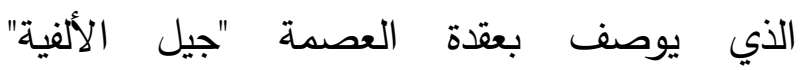
(Twenge,2013) Generation Me هـ-الفروق في مقياسي التصوير الذاتي "السيلفي" والنرجسية تبعاً لمتغير عدد مرات النشر هعي النرير
يتبين من الجدول (7 اله ) أن الفروق على كل من مقياسي التصوير الذاتي "السيلفي" والثخصية النرجسية كانت لصالح الفئة العمرية (أقل من عشرين سنة)، ويعني ذلك أن الفئات العمرية الأصغر أكثر اهتماماً بالتصوير الذاتي "السيلفي"، وهم كذلك أكثر عرضة للنرجسية،

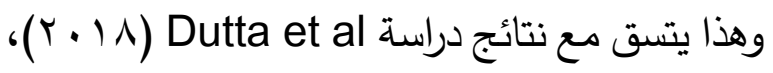
ودراسة Bunker \& Gwalani (2018)، والتي كثفت عن جود فروق بين المراهقين والثباب الذين يمارسون التصوير الذاتي "السيلفي" لصالح المراهين، هين وتختلف مع نتائج دراسة (2015) Weiser والتي لعاي ترى بأن العلاقة بين وأوجهها ونشر صور السيلفى لا

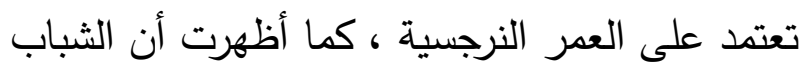

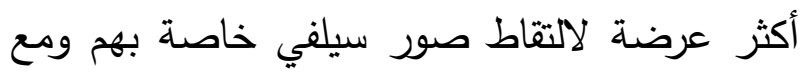

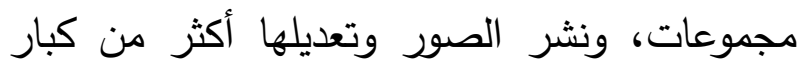
السن، اما بالفروق بحسب العمر في النرجسية هو 
جدول (VV) المتوسطات والانحرافات المعيارية لفئات عدد مرات نشر الصور يومياً على مقياسي الصور الذاتية والنرجسية

\begin{tabular}{|c|c|c|c|}
\hline الانحراف المعياري & المتوسط الحسابي & الفئة العمرية & المقياس \\
\hline 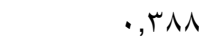 & $r, r q$ & لا يوجد & \multirow{3}{*}{ "السيلفي" التصوير الذاتي } \\
\hline$\cdot, \leqslant 79$ & T,OY & من ו-r مرات & \\
\hline., $0 Y 9$ & T,AV & أكثر من ז مرات & \\
\hline$\cdot, \Sigma \mid V$ & r & لا يوجد & \multirow{3}{*}{ مقياس النرجسية } \\
\hline • r r vo & $\cdot, \leqslant 0$. & من ו-r مرات & \\
\hline$\cdot r \cdot r$ & $\cdot, 001$ & أكثر من ז مرات & \\
\hline
\end{tabular}

يتبين من الجدول (V) أن هناك فروق نسبية بين المتوسطات إحصائية واتجاه نحو إحدى الفئات، فقد تم استخدام نتائج تحليل الحسابية لاستجابات أفراد العينة وفقاً لعدد مرات نشر الصور التباين الأحادي (ANOVA) واختبار شيفيه (Scheffe)، الذاتية يومياً، وللتعرف على ما إذا كان لهذه الفروق دلالة وفيما يلي توضيح النتائج: جدول (1 ا ) تحليل التباين الأحادي (ANOVA) للكشف عن الفروق تبعاً لمتغير عدد مرات نشر الصور الذاتية"السيلفي" يومياً

\begin{tabular}{|c|c|c|c|c|c|c|}
\hline مستوى الدلاية & قيمة (ف) & المربعات & درجة الحرية & مجموع المربعات & مصدر التباين & المقياس \\
\hline \multirow{3}{*}{ دالة } & \multirow{3}{*}{ rV,OYq } & $10, \leqslant 10$ & r & $r \cdot, 979$ & بين المجموعات & \multirow{3}{*}{ مقياس الصور الذاتية } \\
\hline & & \multirow[t]{2}{*}{$\cdot, 07 Y$} & $\varepsilon V V$ & $ץ ฯ \wedge, r \cdot \varepsilon$ & داخل المجموعات & \\
\hline & & & $\leqslant \vee q$ & Y৭৭, rVr & الإجمالي & \\
\hline \multirow{3}{*}{ 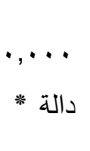 } & \multirow{3}{*}{ I.,YTr } & $\cdot,\{01$ & r & $\cdot, q \cdot r$ & بين المجموعات & \multirow{3}{*}{ مقياس النرجسية } \\
\hline & & \multirow{2}{*}{$\cdot, \cdot \leq \varepsilon$} & 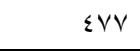 & $r \cdot, q \vee 1$ & داخل المجموعات & \\
\hline & & & $\varepsilon \vee q$ & r I,AVr & الإجمالي & \\
\hline
\end{tabular}

* دالة عند مستوى الالالة (1) 0 . , . )

الذاتية يومياً، ولمعرفة اتجاهات الفروق تم استخدام اختبار شيفيه للفروق البعدية، ويوضح الجدول (T (17) نتائج الفروق: (Scheffe)

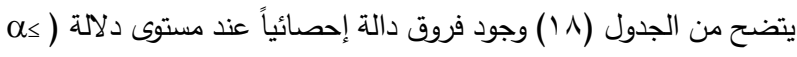
0.05) بين متوسطات استجابات أفراد العينة على مقياسي التصوير الذاتي لإني

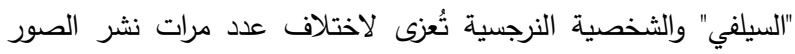
جدول (9 9 ( ) نتائج اختبار شيفيه (Scheffe) للفروق البعدية في مستويي التصوير الأتي والنرجسية تبعاً لمتفير عدد مرات نشر الصور الذاتية يومياً

\begin{tabular}{|c|c|c|c|c|c|}
\hline أكثر من ب مرات & من 1- r مرات & لا يوجد & الحسابي & عدياً مرات نشر الصور الذاتية & المقياس \\
\hline$*, 0 \wedge-$ & $\cdot, Y r-$ & - & $r, r q$ & لا يوجد & \multirow{3}{*}{ الذاتي "السيلفي" التصوير } \\
\hline$*$, ro- & - & • & r,or & من 1- r مرات & \\
\hline- & $*$, ro & $*, 01$ & r,AV. & أكثر من س مرات & \\
\hline$* \cdot, 90-$ & $\cdot, \cdot 1 r$ & - & •, $\leq 7 \pi$ & لا يوجد & \multirow{3}{*}{ مقياس النرجسية } \\
\hline 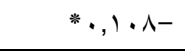 & - & $\cdot, \cdot 1 r-$ & $\cdot, \leqslant 0$. & من ا- r مرات & \\
\hline- & $* \cdot, 1 \cdot 1$ & $\because ., .90$ & $\cdot, 001$ & أكثر من r مرات & \\
\hline
\end{tabular}


النرجسية مع عدد الصور الثخصية، وتفضيل التصوير الذاتي"السيلفي"،

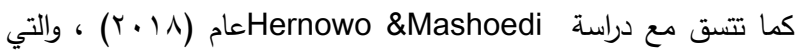

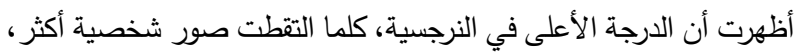

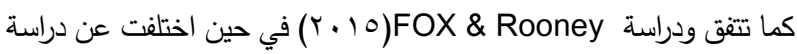
Reed

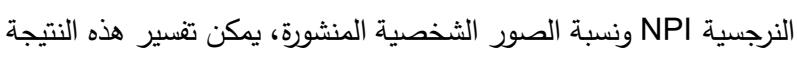

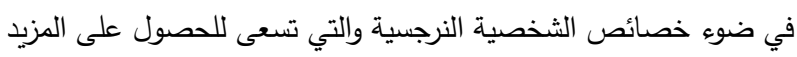

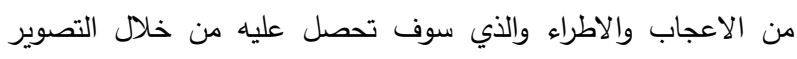
الذاتي"السيلفي" وتكرار سلوك نشر الصور الثخصية. و -الفروق في مقياسي التصوير الذاتي "النيلفي" والنرجسية تبعاً لمتغير لئيل تعديل الصور قبل النشر في النرو
يتبين من نتائج الجدول (9 1) أن اتجاهات الفروق البعدية على مقياسي

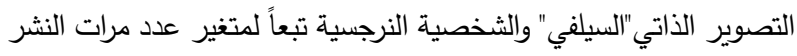

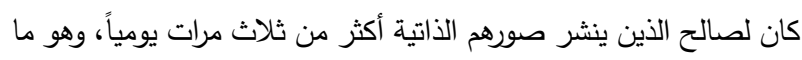
يعني أنهم أكثر التقاطاً للصور الذاتية، وأعلى في مستوى النرجسية، وهذه

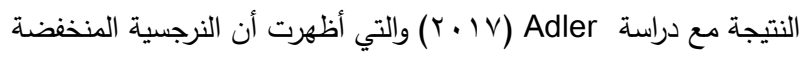

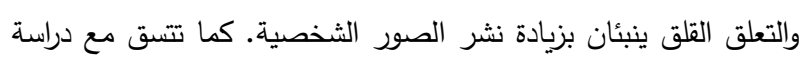

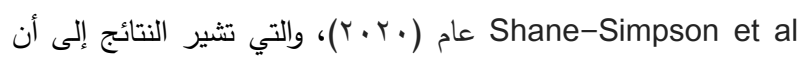

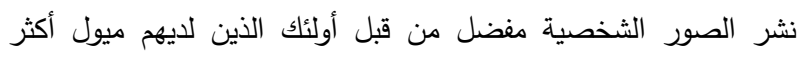
(نرجسية العظمة). ودراسة Anjum\&Kazmi (19. (Y)، والتي أظهرت

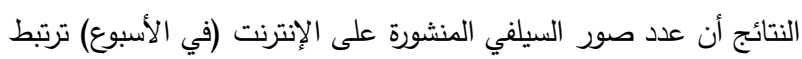

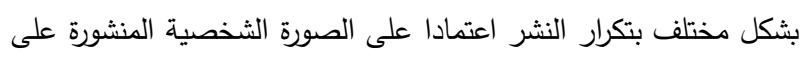

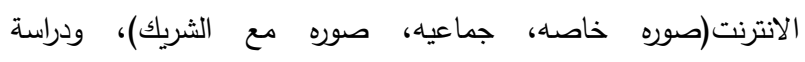
Sukhdeep et al.

\section{جدول ( • r) المتوسطات والانحرافات المعيارية لفئات تعديل الصور قبل نشرها على مقياسي الصور الذاتية والنرجسية}

\begin{tabular}{|c|c|c|c|}
\hline الانحراف المعياري & المتوسط الحسابي & الفئة العمرية & المقياس \\
\hline - $\{\leqslant 7)$ & $r, \cdot V$ & نادراً & \multirow{3}{*}{ "السيلفي" مقياس التصوير الذاتي } \\
\hline$\cdot, r V$. & $r, T r$ & أحياناً & \\
\hline$\cdot, \leqslant 9 \wedge$ & $r, V \uparrow$ & دائماً & \\
\hline •,, $9 \varepsilon$ & $\cdot, \leqslant 0 \leqslant$ & نادراً & \multirow{3}{*}{ مقياس النرجسية } \\
\hline ., r 91 & $\cdot, \leqslant 99$ & أحياناً & \\
\hline • & $\cdot, 011$ & دائماً & \\
\hline
\end{tabular}

يتبين من الجدول (•r) أن هناك فروق نسبية بين المتوسطات الحسابية لاستجابات أفراد العينة وفقاً لتعديل الصور قبل نشرها،

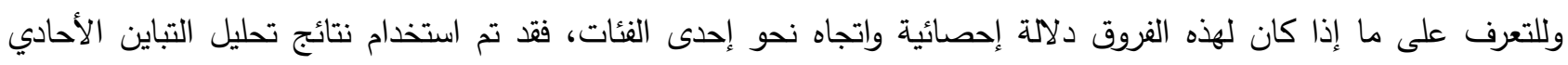
(ANOVA)

\begin{tabular}{|c|c|c|c|c|c|c|}
\hline الدلالة & قيمة (ف) & متوسط & درجة الحرية & مجموع المربعات & مصدر التباين & المقياس \\
\hline \multirow{3}{*}{ دالة" } & \multirow{3}{*}{ rN,or. } & $r \cdot, \Lambda) r$ & r & תו & بين الهجموعات & \multirow{3}{*}{ "السيلفي" التصوير } \\
\hline & & \multirow[t]{2}{*}{$\cdot, 0 \leqslant}$. & $\varepsilon V Y$ & rov, TO. & داخل المجموعات & \\
\hline & & & $\varepsilon \vee q$ & $r ৭ q, r \vee r ~$ & الإجمالي & \\
\hline \multirow{3}{*}{ 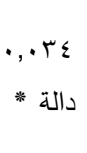 } & \multirow{3}{*}{$r, r q 9$} & $\cdot, 10 \leqslant$ & r & $\cdot r \cdot r$ & بين المجموعات & \multirow{3}{*}{ مقياس النرجسية } \\
\hline & & \multirow{2}{*}{$\cdot, \cdot \leq 0$} & $\varepsilon Y Y$ & $r, 077$ & داخل المجموعات & \\
\hline & & & \&Vq & $r, \wedge V r$ & الإجمالي & \\
\hline
\end{tabular}




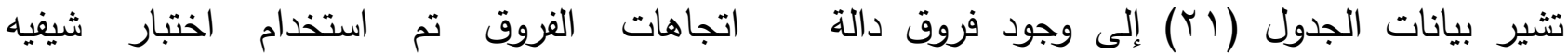

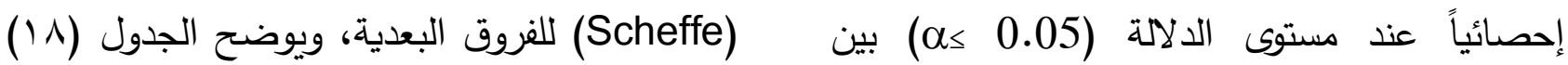
متوسطات استجابات أفراد العينة على مقياسي نتائج الفروق: التصوير الذاتي "السيلفي" والنرجسية وفقاً لاختلاف كلفئ عدد مرات تعديل الصور باستخدام الفلاتر ، ولمعرفة

جدول (r r ) نتائج اختبار شيفيه (Scheffe) للفروق البعدية في مستويي التصوير الذاتي "السيلفي" والنرجسية تبعاً لمتفير تعديل الصور باستخدام الفلاتر

\begin{tabular}{|c|c|c|c|c|c|}
\hline دائماً & أحياناً & 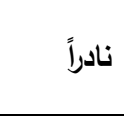 & المتوسط & تعديل الصور & المقياس \\
\hline$*, 79 .-$ & $* .070-$ & - & $r, \cdot V$ & ن ن ادراً & \multirow{3}{*}{ مقياس $\quad$ الأتي "السيلفي" } \\
\hline$\cdot, 1$ YO- & - & $*, 070$ & rT, & أحياناً & \\
\hline- & ., 1Yo & $*, 79$. & $Y, V Y$ & دائماً & \\
\hline - , , & $\cdot, \cdot \leq \varepsilon \leq-$ & - & $\cdot, \leqslant 0 \leqslant$ & ن ن نادراً & \multirow{3}{*}{ مقياس النرجسية } \\
\hline$\cdot, \cdot 19-$ & - & $\cdot, \cdot \leq \varepsilon$ & $\cdot, \leqslant 99$ & أحياناً & \\
\hline- & $\cdot, .19$ & זד.,. & $\cdot, 011$ & دائماً & \\
\hline
\end{tabular}

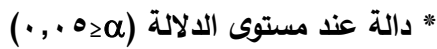

يركزون اهتمامهم على ذاتهم بشكل أكبر ، ويعتدون أنهم أكثر ذكاء وجاذبية

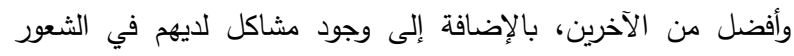

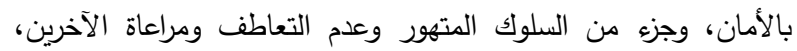
بالإضافة لبعض سمات معاداة المجتمع، والميل إلى تضخيم الذات، وتؤكد FOX Jesse يساعد في تأكيد" تضخيم الذات "عند هؤلاء الأفراد. ويفسر ذلك بمشاعر لـأر

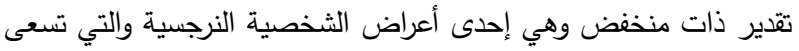
للحصول على اعجاب الاخرين والمديح والاطراء. التوصيات: توصى الدراسة الحالية على إجراء المزيد من الدراسات العربية

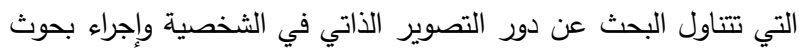

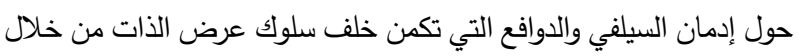

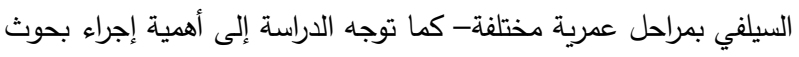

يتضح من نتائج الجدول (rr) أن اتجاهات الفروق البعدية على مقياس

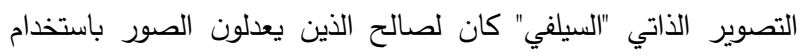

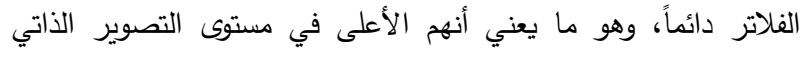

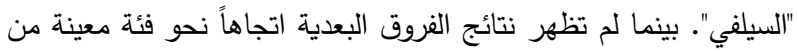

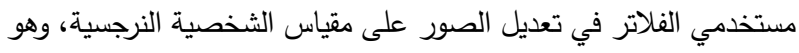
ما يعني أن جميع مستخدمي الفلاتر في تعديل الصور الذاتية لديهم فئه

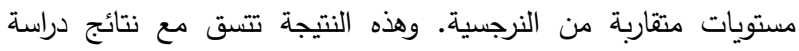
Sorokowski et al

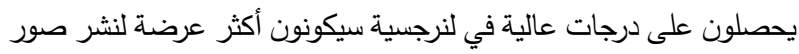
شخصية على مواقع التواصل الاجتماعي، ومواقع إعلامية أكثر من الأفراد

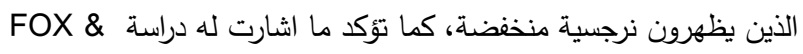
Rooney

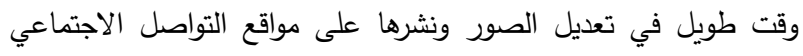




\section{مريم حميد أحمد اللحياني}

ov.

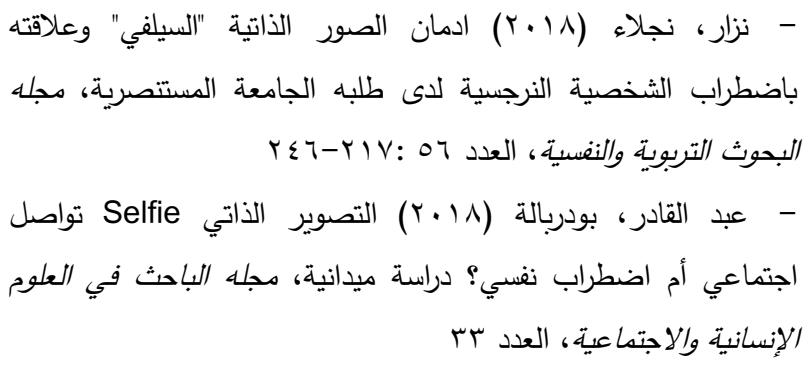

\section{ثانيا المراجع الانجليزية}

- $\quad$ Adler Nancy. (2017). Who Posts Selfies and Why?: Personality, Attachment Style, and Mentalization as Predictors of Selfie Posting on Social Media, degree of Doctor of Philosophy, The Graduate Center, City University of New York. CUNY Academic Works. https://academicworks.cuny.edu/cgi/viewcontent.cgi?article=3338\&co ntext=gc etds

Alfailakawi Yousef. (2018). What Do Selfies Say about Young Kuwaitis? Media Watch 9(2); 167-181. 10.15655/mw/2018/v9i2/49388

Alloway, T., Runac, R., Qureshi, M. \& Kemp, G. (2014). Is Facebook Linked to Selfishness? Investigating the Relationships among Social Media Use, Empathy, and Narcissism. Social Networking, 3, 150-158. doi: 10.4236/sn.2014.33020

American Psychiatric Association (2013): Diagnostic and Statistical Manual of Mental Disorders .5th .edition .Washington ,DC: American Psychiatric Association

- American Psychiatric Association, DSM-5 Task Force. (2013). Diagnostic and statistical manual of mental disorders: DSM$5^{\mathrm{TM}} \quad$ (5th ed.). American Psychiatric Publishing, Inc.. https://doi.org/10.1176/appi.books.9780890425596

Ames, Daniel R., Rose, Paul \& Anderson, Cameron P. (2006). The NPI-16 as a short measure of narcissism. Journal of Research in Personality, $\quad 40, \quad 440$ 450.https://www0.gsb.columbia.edu/mygsb/faculty/research/pubfiles/ 1005/npi16 jirp.pdf

Anjum, Ambreen, \& Kazmi Rubab.(2019). Narcissism and body-esteem: Distinct motivations for selfie posting behavior among adolescents. Journal of Gender and Social Issues, 18 (1), p. 109.

Balakrishnan, Janarthanan \& Griffiths, Mark. (2018). An Exploratory Study of BSelfitis and the Development of the Selfitis Behavior Scale. Int J Ment Health Addiction. (16). 722-736. https://www.ncbi.nlm.nih.gov/pmc/articles/PMC5986832/

- $\quad$ Barry, C. T., Doucette, H., Loflin, D. C., Rivera-Hudson, N., \& Herrington, L. L. (2017). "Let me take a selfie": Associations between self-photography, narcissism, and self-esteem. Psychology of Popular Media Culture, 6(1), 48-60. https://doi.org/10.1037/ppm0000089

- $\quad$ Bentley Sarah J. (2019). The Selfie Phenomenon: Exploring the Evolution of the Self-Portrait in the Photography Classroom, Master Theses, Western Michigan University, United States of America https://scholarworks.wmich.edu/masters theses/4294

- Berry, D. S., Finch-Wero, J. L. (1993). Accuracy in face perception: A view from ecological psychology. Journal of personality, 61(4), 497-520.

- $\quad$ Besser, A., \& Zeigler-Hill, V. (2011). Pathological forms of narcissism and perceived stress during the transition to the university: The mediating role of humor styles. International Journal of Stress Management, 18(3):197-221.

$$
\begin{aligned}
& \text { مقارنات عبر ثقافيه لمزيد من الفهم لظاهره التصوير الذاتي "السيلفي" ودورها } \\
& \text { في تشكيل نرجسية الافراد بصورتها السوية والمرضية. } \\
& \text { المراجع } \\
& \text { أولا المراجع العربية } \\
& \text { - العاسمي، رياض. (10 + (1) علم النفس الإيجابي الإكلينيكي-الجزء } \\
& \text { الثاني، عمان: دار الإعصار }
\end{aligned}
$$

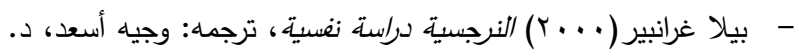

$$
\begin{aligned}
& \text { ط، منشورات وزارة الثقافة، دمشق }
\end{aligned}
$$

Biolcati, R., \& Passini, S. (2018). Narcissism and self-esteem: Different motivations for selfie posting behaviors. Cogent Psychology, $5(1)$, Article

1437012. https://doi.org/10.1080/23311908.2018.1437012

Blanchette, A. (2017, January 28). Botox is booming among millennials - some as Young as 18. The Star Tribune. Retrieved from http://www.startribune.com

Boursiera Valentina, Gioiaa Francesca\& Griffiths Mark D.(2020).Selfie-engagement on social media: Pathological narcissism, positive expectation, and body objectification - Which is more influential?, Behaviors Reports, Vol: 11, p: 100263

Brandt R. (2014). Google divulges numbers at I/O: 20 Billion texts, 93 million selfies and more. Silicon Valley Business Journal. 25: 44-8. Retrieved http://www.bizjournals.com/sanjose/news/2014/06/25/googledivulges-numbers-at-i-o-20- billion-texts-93.html

Braun, S. (2017). Leader Narcissism and Outcomes in Organizations: A Review at Multiple Levels of Analysis and Implications for Future Research. Frontiers in psychology, 8 (773), 122.

Braun, S., Aydin, N., Frey, D., \& Peus, C. (2018). Leader narcissism predicts malicious envy and supervisor-targeted counterproductive work behavior: Evidence from field and experimental research. Journal of Business Ethics, 151(3), 725741. https://doi.org/10.1007/s10551-016-3224-5

- $\quad$ Bunker, L. N., \& Gwalani, M. (2018). Narcissism, Body-Esteem and Selfie-taking behaviour among Teens and Adolescents, International Journal of Research and Analytical Reviews, 5 (3), 391395.

Cain, N. M., Pincus, A. L., \& Ansell, E. B. (2008). Narcissism at the crossroads: Phenotypic description of pathological narcissism across clinical theory, social/personality psychology, and psychiatric diagnosis. Clinical Psychology Review, 28, 638-656.

- Charoensukmongkol, P. (2016). Exploring personal characteristics associated with selfie-liking. Cyberpsychology: Journal of Psychosocial Research on Cyberspace, 10(2),7. doi: 10.5817/CP2016-2-7

- $\quad$ Dhir, A., Pallesen, S., Torsheim, T., \& Andreassen, C. S. (2016). Do age and gender differences exist in selfie-related behaviours? Computers in Human Behavior, 63, 549555. https://doi.org/10.1016/j.chb.2016.05.053

Dom Joy \& Venkatachalam J. (2019). Personality and SelfieLiking Behaviour among College Students, The research journal of social sciences, 10( 6).293-299

- Dutta E, Sharma P, Dikshit R, Shah N, Sonavane S, Bharati A, Sonavane S, Desousa A (2018). Attitude toward Selfie Taking and Its Relation to Body Image and Narcissism in Medical Students, Indian 
Journal Psychol Med. 40(1), 17-21. doi: 10.4103/IJPSYM.IJPSYM_169_17.

Eler, Alicia. (2017). The Selfie Generation: How Our SelfImages Are Changing Our Notions of Privacy, Sex, Consent, and Culture. New York: Skyhorse Publishing

Finkel, E. J., Campbell, W. K., Buffardi, L. E., Kumashiro, M., $\&$ Rusbult, C. E. (2009). The metamorphosis of Narcissus: Communal activation promotes relationship commitment among narcissists. Personality and Social Psychology Bulletin, 35(10), 12711284. https://doi.org/10.1177/0146167209340904

Firestone, L. $(Y \cdot I r$, October 10$)$. Is social media to blame for the rise in narcissism? Huffington Post.

- $\quad$ Foster, J. D., \& Campbell, W. K. (2007). Are there such things as "Narcissists" in social psychology? A taxometric analysis of the Narcissistic Personality Inventory. Personality and Individual Differences, 43(6), 13211332. https://doi.org/10.1016/j.paid.2007.04.003

Foster, J. D., Campbell, W. K., \& Twenge, J. M. (2003). Individual differences in narcissism: Inflated self-views across the lifespan and around the world. Journal of Research in Personality.37(6):469-486.https://doi.org/10.1016/S00926566(03)00026-6

Fox, Jesse \& Rooney, Margaret C. (2015). The Dark Triad and trait self-objectification as predictors of men's use and self-presentation behaviors on social networking sites. Personality \& Individual Differences, 76, 161-165. doi: 10.1016/j.paid.2014.12.017

Grenyer, B.F.S. (2013). Understanding and treating pathological narcissism, Chapter: Historical overview of pathological narcissism, .Washington, DC: American Psychological Association, Editors: J.S. Ogrodniczuk, pp.15-26. https://deepblue.lib.umich.edu/bitstream/handle/2027.42/57606/skonra $\underline{\text { th_2.pdf?sequence }=2}$

Griffiths, M. D., \& Balakrishnan, J. (2018). The psychosocial impact of excessive selfie-taking in youth: a brief overview. Education and Health, 36(1), 3-6.

Halpern, D., Valenzuela, S., \& Katz, J. E. (2016). "Selfie-ists" or "Narci-selfies"?: A cross-lagged panel analysis of selfie-taking and narcissism. Personality and Individual Differences, 97, 98-101.

- Hernowo Fadilla Andita \& Mashoedi Sri Fatmawati. (2018). The Correlation of Narcissism and Selfie-Posting Behavior on Instagram among Millennials,Advances in Social Science, Education and Humanities Research, 139;212-216.

Hess, A. (2015b). The selfie assemblage. International Journal of Communication, 9, 1629- 1646. Retrieved from http://ijoc.org/index.php/ijoc/article/view/3147/1389

Katz, J. E., Crocker, E. T. (2015). Selfies and photo messaging as visual conversation: Reports from the United States, United Kingdom and China. International Journal of Communication,9(1):1861-1872.

https://ijoc.org/index.php/ijoc/article/view/3180/1405

Kennedy, E. J., Lawton, L., \& Plumlee, E. L. (2002). Blissful ignorance: The problem of unrecognized incompetence and academic performance. Journal of Marketing Education, 24(3). 243-252.

Kevin S.Carlson, Per F.Gjerde. (2009). Preschool personality antecedents of narcissism in adolescence and young adulthood: A 20year longitudinal study. Journal of Research in Personality 43 (4), 570578

Kim, J. W., \& Chock, T. M. (2016). Personality traits and psychological motivations predicting selfie-posting behaviors on social networking sites. Telematics and Informatics, 34(5), 560-571

- Kiprin B. (2013). Go Selfie Yourself. Available at: https://borislavkiprin.com/2013/12/13/go-selfie-yourself/
- $\quad$ Lee, J. A., \& Sung, Y. (2016). Hide-and-seek: narcissism and "Selfie"-related behavior. Cyber psychology, Behavior, and Social Networking, 19(5), 347-351

- $\quad$ Lenhart A., Purcell K., Smith A., Zickuhr K. (2010). Social Media and Mobile Internet Use Among Teens and Young Adults. Pew Internet and American Life Project. Available at: https://files.eric.ed.gov/fulltext/ED525056.pdf.

- $\quad$ McCain, J. L., Borg, Z. G., Rothenberg, A. H., Churillo, K. M., Weiler, P., \& Campbell, W. K. (2016). Personality and Selfies: Narcissism and the Dark Triad. Computers in Human Behavior, 64, 126-133. https://doi.org/10.1016/j.chb.2016.06.050

- Mehdizadeh, S. (2010). Self-Presentation 2.0: Narcissism and Self-Esteem on Facebook. Cyberpsychology, Behavior, and Social Networking, 13(4):357-364. https://doi.org/10.1089/cyber.2009.0257

- $\quad$ Miller, J. D., \& Campbell, W. K. (2008). Comparing clinical and social-personality conceptualizations of narcissism. Journal of Personality, 76(3):449-76

- $\quad$ Miller, J. D., Lynam, D. R., Hyatt, C. S., \& Campbell, W. K. (2017). Controversies in Narcissism. Annual Review of Clinical Psychology, 13(1), 291-315. DOI: https:// doi.org/10.1146/annurevclinpsy-032816-045244

- $\quad$ Muscanell, N. L., \& Guadagno, R. E. (2012). Make new friends or keep the old: Gender and personality differences in social networking use. Computers in Human Behavior, 28(1), 107112.10.1016/j.chb.2011.08.016

- $\quad$ Nevid, J. S., Rathus, S. A., \& Greene, B. (2003). Abnormal psychology in a changing world (5th ed.). Prentice Hall/Pearson Education.

- Nicholas S.Holtzman \&Michael J.Strube. (2010). Narcissism and attractiveness, Journal of Research in Personality , 44, (1), 133136

Ong, E. Y., Ang, R. P., Ho, J. C., Lim, J. C., Goh, D. H., Lee, C. S., \& Chua, A. Y. (2011). Narcissism, Extraversion and Adolescents' Self-Presentation on Facebook. Personality and Individual Differences50 (2), 180-185.

Oxford Dictionaries (2013)'Selfie' Origins: Oxford Dictionaries 2013 Word of the Year First Used in Australian Online Forum By: International Business Times, Tue, 19 Nov.

- Panek, E. T., Nardis, Y., \& Konrath, S. (2013). Mirror or Megaphone?: How relationships between narcissism and social networking site use differ on Facebook and Twitter. Computers in Human Behavior, 29(5), 2004-2012

- Pew Research Center. (2014, March 4). More than half of millennials have shared a selfie.https://www.pewresearch.org/facttank/2014/03/04/more-than-half-of-millennials-have-shared-a-selfie/

Pincus, A. L., \& Lukowitsky, M. R. (2010). Pathological narcissism and narcissistic personality disorder. Annual Review of Clinical Psychology, 6, 421-446.

Pincus, A. L., Ansell, E. B., Pimentel, C. A., Cain, N. M., Wright, A. G., \& Levy, K. N. (2009). Initial construction and validation of the Pathological Narcissism Inventory. Psychological Assessment, 21, 365-379.

- $\quad$ Pounders, K., Kowalczyk, C. M., \& Stowers, K. (2016). Insight into the motivation of selfie postings: Impression management \& selfesteem. European Journal of Marketing, 50(9), 1879-1892. doi:10.1108/EJM-07-2015-0502

Reed, M. (2015). Narcissism and the selfie: Investigating the millennial narcissism on Instagram (Honors college thesis, Andrews University). Retrieved from http://digitalcommons.andrews.edu/honors/109 
- $\quad$ Rosenthal Seth. (2010). Narcissism and Leadership: A Review and Research Agenda, Center for Public Leadership, file:///C:/Users/My\%20Hp/Downloads/RosenthalNarcissismandLeadership\%20(1).pdf

Sedgewick, J. R., Flath, M. E., \& Elias, L. J. (2017). Presenting your best self (ie): The influence of gender on vertical orientation of selfies on Tinder. Frontiers in Psychology, 8, Article 604. https://doi.org/10.3389/fpsyg.2017.00604

Senft, T. M.; Baym, N. K. (2015). What does the selfie say? Investigating a global phenomenon. International Journal of Communication. 9, p. 1588- 1606.

Shaha, Reena \& Tewarib, Ruchi. (2016). Demystifying 'selfie': a rampant social media activity, Behaviour \& Information Technology. 35 (10), 864-871

Shane-Simpson Christina, Obeid Rita, Schwartz Anna, AbiHabib Rudy (Y.r.) I Love my Selfie! Demographics, Culture, and Narcissism Predict Selfie-Posting Behaviors, Computers in Human Behavior, 104:106158.

Shevlin, M., Walker, S., Davies, M. N., Banyard, P., \& Lewis, C. A. (2003). Can you judge a book by its cover? Evidence of selfstranger agreement on personality at zero acquaintance. Personality and Individual Differences, 35(6), 1373-1383.

Sorokowski, P., Sorokowska, A., Oleszkiewicz, A., Frackowiak , T., Huk, A., \& Pisanski, K. (2015). Selfie posting behaviors are associated with narcissism among men. Personality and Individual Differences, 85, 123-127. doi: 10.1016/j.paid.2015.05.004

Souza, F., de Las Casas, D., Flores, V., Youn, S., Cha, M., Quercia, D., \& Almeida, V. (2015, November). Dawn of the selfie era: The whos, wheres, and hows of selfies on Instagram. Proceedings of the 2015 ACM on conference on online social networks (pp. 221-231)
Sukhdeep, K., Maheswarisk, S. K., \& Sharma, P. (2018). Narcissistic personality and selfie taking behavior among college students. International Journal of Medical and Health Research, 4(5), 56-60.

- $\quad$ Sung, Y., Lee, J. A., Kim, E., \& Choi, S. M. (2016). Why we post selfies: Understanding motivations for posting pictures of oneself. Personality and Individual Differences, 97, 260265.https://doi.org/10.1016/j.paid.2016.03.032

Twenge J. M. (2013). The evidence for generation me and against generation we. Emerging Adulthood 1(1): 11-16. doi: $10.1177 / 2167696812466548$

Vazire, S., Naumann, L. P., Rentfrow, P. J., \& Gosling, S. D. (2008). Portrait of a narcissist: Manifestations of narcissism in physical appearance. Journal of Research in Personality, 42(6), 1439-1447.

Weiser, E. B. (2015). \#Me: Narcissism and its facets as predictors of selfie-posting frequency. Personality and Individual Differences, 86, 477-481.

Westerman, J. W., Bergman, J. Z., Bergman, S. M., \& Daly, J. P. (2012). Are universities creating millennial narcissistic employees? An empirical examination of narcissism in business students and its implications. Journal of Management Education, 36(1). 5-32.

Wickel, Taylor. M., (2015). Narcissism and Social Networking Sites: The Act of Taking Selfies. The Elton Journal of Undergraduate Research in Communications. 6 (1), 1-2.

- $\quad$ Zeigler-Hill, V., Green, B. A., Arnau, R. C., Sisemore, T. B., \& Myers, E. M. (2011). Trouble ahead, trouble behind: Narcissism and early maladaptive schemas. Journal of Behavior Therapy and $\begin{array}{lll}\text { Experimental } & \text { Psychiatry, } & 42(1)\end{array}$ doi:10.1016/j.jbtep.2010.07.004 


\title{
"Selfie" as a predictor of the narcissistic personality of High School teachers and Students in Makkah Al Mukarramah
}

\author{
DR. MARIAM HAMEED AHMED ALLAHYANI \\ Associate Professor- Department of Psychology \\ College of Education - Umm Al-Qura University
}

\begin{abstract}
Selfie and the narcissistic personality, to determine the relationship between them, the degree of prediction of "Selfie" through the narcissistic personality, and to reveal the differences in the level of "Selfie" and the narcissistic personality according to the variables of the study. To achieve the objectives of the current study, the predictive descriptive approach was used. Moreover, the study used the "Selfie" scale for Balakrishnan \& Griffiths and the narcissistic personality scale for Ames, Rose, Cameron .It was applied to a sample of (480) individuals, (255) male and female teachers and (225) male and female students. The study concluded the following: There is a statistically positive and significant correlation between the narcissistic personality and Selfie with its six dimensions. The results of the narcissistic personality are also predicted through Selfie which contributes to $(22 \%)$ to the change in the narcissistic personality of teachers and to $(31 \%)$ to the change in students. The results also revealed the existence of statistically significant differences between students and teachers on "Selfie" and narcissistic personality scales for students. There were no statistically significant differences between males and females on "Selfie" and narcissistic scales, while it revealed indicative differences on "selfie" and narcissism "scales according to the age group for the younger age group. It showed indicative differences for both scales of "selfie" and the narcissistic personality for the difference in the number of sharing selfie and the modification of pictures using filters in for those who publish more and always modify the photos .
\end{abstract}

Key words: "Selfie", Narcissistic Personality, Mental disorder, Makkah. 